\title{
How fast and how often: The pharmacokinetics of drug use are decisive in addiction
}

\section{Florence Allain $^{\text {a }}$, Ellie-Anna Minogianis ${ }^{a}$, David C.S. Roberts ${ }^{b}$, Anne-Noël Samaha ${ }^{\text {a,c, }, *}$}

a Department of Pharmacology, Faculty of Medicine, Université de Montréal, Montreal, QC, Canada H3C 3J7

b Department of Physiology and Pharmacology, Wake Forest University Health Sciences, Winston-Salem, NC 27157, USA

c CNS Research Group, Faculty of Medicine, Université de Montréal, Montreal, QC, Canada H3C 3J7

* Corresponding author at: Université de Montréal, Department of Pharmacology, Faculty of Medicine, Montreal, QC, Canada H3C 3J7. Tel.: +1 514343 6111x32788; fax: +1 514343 2291. E-mail address: Anna.samaha@umontreal.ca (A.-N. Samaha).

\begin{abstract}
How much, how often and how fast a drug reaches the brain determine the behavioural and neuroplastic changes associated with the addiction process. Despite the critical nature of these variables, the drug addiction field often ignores pharmacokinetic issues, which we argue can lead to false conclusions. First, we review the clinical data demonstrating the importance of the speed of drug onset and of intermittent patterns of drug intake in psychostimulant drug addiction. This is followed by a review of the preclinical literature demonstrating that pharmacokinetic variables play a decisive role in determining behavioural and neurobiological outcomes in animal models of addiction. This literature includes recent data highlighting the importance of intermittent, 'spiking' brain levels of drug in producing an increase in the motivation to take drug over time. Rapid drug onset and intermittent drug exposure both appear to push the addiction process forward most effectively. This has significant implications for refining animal models of addiction and for better understanding the neuroadaptations that are critical for the disorder.
\end{abstract}

\section{Keywords}

Drug addiction, Pharmacokinetics, Cocaine, Route of drug intake, Speed of drug delivery, Intermittent drug exposure.

\section{Highlights}

- Drug pharmacokinetics determine neurobehavioural changes linked to addiction

- The drug addiction field often ignores pharmacokinetic issues

- Rapid drug onset and intermittent use both facilitate the transition to addiction

- This has implications for refining animal models of the process of addiction 


\section{Contents}

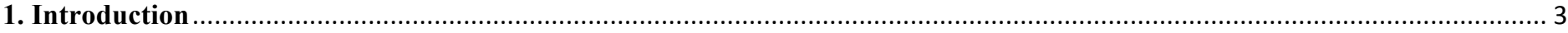

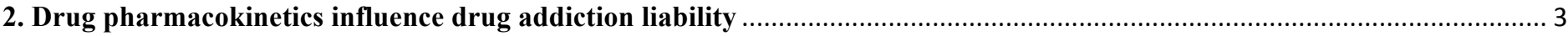

3. Preclinical studies show that drug pharmacokinetics determine brain and behaviour effects relevant to addiction .............. 4

3.1. The effects of pharmacokinetic variables in intravenous drug self-administration models .................................................. 7

3.2. Drug taking (consummatory) versus drug seeking (appetitive) responses......................................................................... 7

3.3. Pharmacokinetic variables influence drug-taking (consummatory) behaviour .................................................................... 8

3.3.1. Drug-taking behaviour during limited daily access to drug ............................................................................... 8

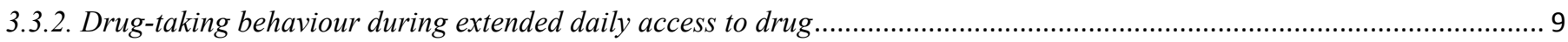

3.4. Pharmacokinetic variables influence drug-seeking (appetitive) behaviour.......................................................................... 10

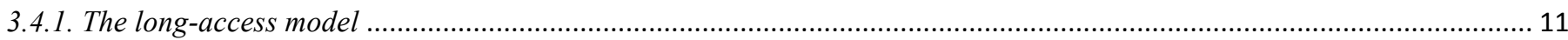

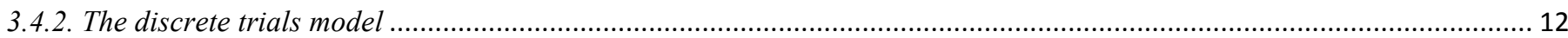

3.4.3. Daily testing under a progressive ratio schedule of cocaine reinforcement................................................................. 12

3.4.4. A new model: Intermittent access to drug during a long-access session ..................................................................... 12

3.5. Pharmacokinetics determine the neuroplasticity evoked by drugs ................................................................................... 13

4. Why is it useful to study the temporal dynamics of drug delivery as an active principle in addiction? ............................. 14

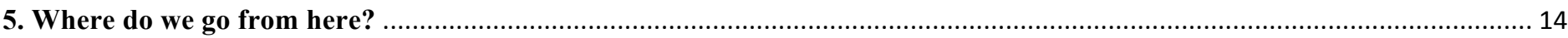

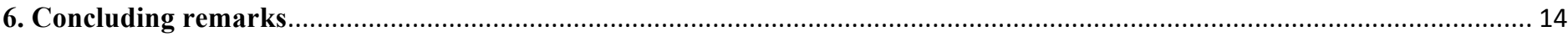

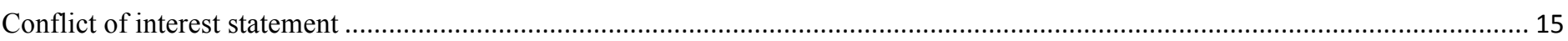

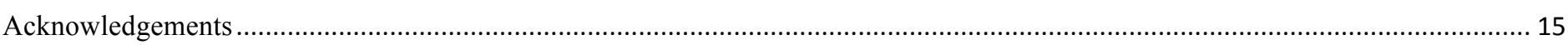

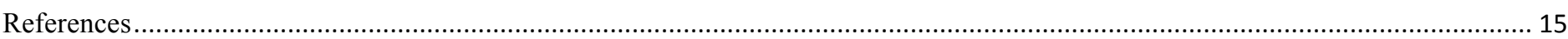




\section{Introduction}

Amongst people who use drugs, some keep control over their drug use while others develop addiction. What accounts for this differential vulnerability? Like any complex disease, "the development of addiction depends on the interaction of agent, host and environment" (O'Brien, 2008). With this reality, it becomes clear that to identify the brain changes that are critical to addiction, it is important that we understand how agent, host and environment each influence the response to drugs of abuse. The roles of the individual and of the environment are studied extensively. Much less attention has been paid to characteristics of the 'agent', such as drug pharmacokinetics. In the context of drug addiction, important pharmacokinetic parameters include how much drug gets to the brain (achieved dose), how fast drug levels rise in the brain (rate of drug onset) and how often they rise and fall (intermittency).

Thirty-five years ago, Robert Post emphasized the importance of the temporal dynamics of stimulation by drugs and other stimuli in '...determining the direction and magnitude of adaptive response following repeated presentation' (Post, 1980). When considering the response to a drug of abuse or any pharmacological agent for that matter, pharmacokinetics determine the pharmacodynamics. That is, pharmacokinetics govern the ability of drugs to interact with transporters and receptors, and to influence intra-cellular signalling cascades. The same drug can have markedly different - sometimes opposite - effects on brain and behaviour depending on whether it is injected intravenously (i.v.), or into the intraperitoneal (i.p.) cavity, administered through the skin, taken orally or given chronically in a subcutaneous (s.c.) osmotic minipump. This is because different routes of drug administration produce markedly different pharmacokinetic profiles. This is why a drug that can produce addiction when smoked or injected can be used to treat addiction when given orally (methadone) or in a patch (nicotine). Similarly, amphetamine formulated to produce slowly rising and steadystate levels of drug in the brain is currently used as pharmacotherapy for cocaine addiction (Negus and Henningfield, 2015). Methadone, nicotine and amphetamine are striking examples from the clinical literature showing that manipulation of pharmacokinetic variables can fundamentally change the behavioural effects of drugs - rather than having abuse potential they might actually have therapeutic potential. As will be shown below, pharmacokinetics determine all drug effects that are relevant to addiction.

The influence of pharmacokinetics on the response to drugs of abuse remains largely unstudied, save for dose. This is in part because in the addiction field, it is widely assumed that the amount of drug exposure largely determines outcome (Ahmed, 2012, Benowitz and Henningfield, 1994 and Jonkman et al., 2012). Some have even suggested the existence of a 'critical level' of drug exposure beyond which "addiction-causing neuropathological processes could be set in motion" (Ahmed, 2012). Drug pharmacokinetics are often regarded as secondary, simply a means to vary the amount of drug reaching the brain.
This assumption is dangerous. Variation in the pharmacokinetic profile of a drug can produce different effects even when the same amount of drug reaches the brain. In other words, "how fast" and "how often" can be more important than "how much" in determining functional outcome. This principle is at the core of the present review. The general principles that will be discussed apply across drug classes. However, it is not feasible to review all drug classes. Opiates, alcohol and nicotine present their own specific pharmacokinetic issues and these deserve to be reviewed in depth. Here we will focus on cocaine. We do so for three principle reasons. First, cocaine can be snorted, smoked or injected and these different routes result in very different pharmacokinetic profiles. Second, the clinical literature emphasizes the importance of pharmacokinetics in cocaine addiction (Hatsukami and Fischman, 1996). Third, in animal studies, cocaine is most often used as a prototypical drug of abuse to investigate the contributions of pharmacokinetics to drug response. Thus, here we review the evidence showing that in addition to drug dose, the speed of drug onset and the intermittency of drug exposure both determine brain and behaviour changes that are relevant to addiction, particularly cocaine addiction.

\section{Drug pharmacokinetics influence drug addiction liability}

The clinical data are clear; the faster drugs reach the brain, the more likely it is that addiction will develop. Drugs of abuse are often taken by the i.v., smoked, oral or intranasal routes. The route of drug administration determines both how fast (rise time) and how much (area under the curve) drug reaches the general circulation and ultimately, the brain (see Fig. 1). However, rise time can be more predictive of addiction liability than other parameters such as area under the curve. Smoking and injecting are the two fastest and most efficient methods of getting drug into the bloodstream (Cone, 1995, Cone, 1998 and Evans et al., 1996). Peak venous plasma levels of cocaine or radiolabelled cocaine are reached in $2-5 \mathrm{~min}$ following i.v. injection or smoking, and 30-60 min after intranasal administration (Cone, 1998, Javaid et al., 1978, Jeffcoat et al., 1989 and Van Dyke et al., 1976). (Of note, peak arterial plasma levels of drug are reached earlier than peak venous plasma levels, for example time to peak arterial cocaine levels after smoking or intravenous injection is $15 \mathrm{~s}$; Evans et al., 1996). The oral and intranasal routes result in slower absorption rates, which in turn result in lower blood concentrations, over a longer period of time (Cone, 1995 and Cone, 1998). Peak plasma levels of drug correlate well in time with the subjective effects of drugs. For a drug like cocaine, for example, the maximum self-reported 'high' is reached 1-5 min after intravenous injection, and 15-20 min after intranasal administration (Evans et al., 1996 and Javaid et al., 1978). 


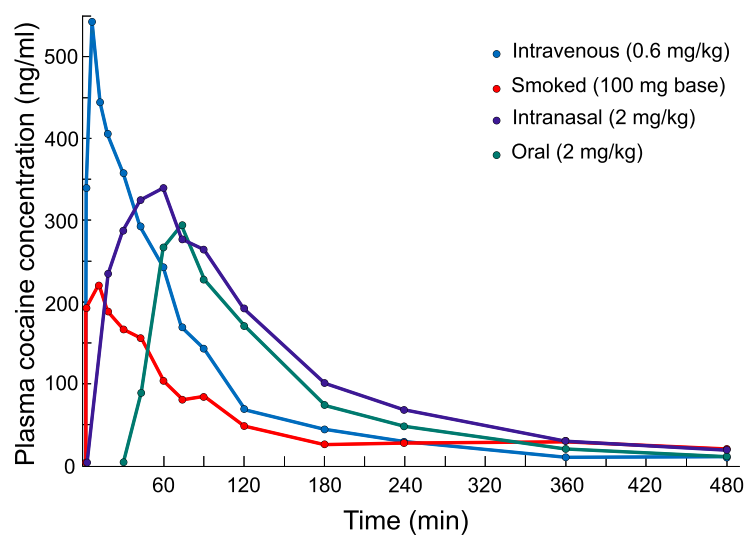

Fig. 1. The pharmacokinetic profiles of plasma cocaine levels in humans as a function of the route of drug administration. Plasma cocaine levels rise sharply and decline rapidly when cocaine is injected intravenously or smoked. In contrast, plasma cocaine levels rise and decline more slowly following intranasal or oral administration of the drug. Data represent the mean for 10 human subjects in each condition. Adapted from Jones (1990).

Addiction is more likely and more severe in individuals who take drugs via rapid routes of drug delivery. For instance, addiction to cocaine, amphetamine, methamphetamine, nicotine or heroin is more probable in people who consume these drugs via smoking or i.v. injection than in individuals who use slower routes of drug administration (e.g., the intranasal or transdermal routes; Barrio et al., 2001, Budney et al., 1993, Carpenter et al., 1998, Ferri and Gossop, 1999, Gossop et al., 1992, Gossop et al., 1994, Hatsukami and Fischman, 1996, Hughes, 1989, Rawson et al., 2007, Van Dyke and Byck, 1982, Volkow and Swanson, 2003 and Winger et al., 1992). Compared to intranasal drug users, individuals who smoke or inject drugs i.v. also use drugs more frequently, for a longer time, spend more money on drugs, report a greater loss of control over drug taking and are more likely to overdose (Barrio et al., 2001, Carpenter et al., 1998, Ferri and Gossop, 1999, Gossop et al., 1992, Gossop et al., 1994, Hatsukami and Fischman, 1996, Hughes, 1989, Rawson et al., 2007, Van Dyke and Byck, 1982, Volkow and Swanson, 2003 and Winger et al., 1992). Finally, users who smoke or inject drugs have more health-threatening patterns of drug use (Carpenter et al., 1998, Ferri and Gossop, 1999, Gossop et al., 1992, Hatsukami and Fischman, 1996, Hughes, 1989, Rawson et al., 2007 and Winger et al., 1992), and they suffer more harm, including contracting blood borne viruses such as HIV and hepatitis C, experiencing drug-induced paranoid psychosis, and dying of an overdose (Brady et al., 1991, Gossop et al., 1992, Hatsukami and Fischman, 1996, Roncero et al., 2012 and Winger et al., 1992).

The oral route is much slower and therefore carries less addiction liability. However, the risk exists and drug manufacturers make efforts to reduce the speed of absorption of certain potentially addictive medications. For example, amphetamine (Adderall), methylphenidate (Ritalin) and phenmetrazine (Preludin) are being designed to reduce the speed of brain uptake and the ability of users to smoke or inject the drugs (Connor and Steingard, 2004 and Spencer et al., 2006).

The intermittency of drug use is also a recurrent theme in the addiction literature. Systematic research on the temporal pattern of drug use in humans is scarce. There are however anecdotal reports and general agreement that intermittency of intake is a defining feature of psychostimulant drug addiction. There appear to be two, possibly independent intermittency phenomena. The first is the 'abstinence period', which can last for days or weeks. The second is the inter-dosing interval within a bout of intoxication. Drug users adopt intermittent patterns of use, and this is seen both within and between a bout of intoxication. The notion of intermittent drug use in addicts, particularly for drugs like cocaine, is emphasized in classic writings on addiction (Gawin and Kleber, 1986 and O'Brien, 2001), and is supported by anecdotal reports and observational studies primarily involving experienced drug users. For example, Ward et al. (1997) state "anecdotal reports from the majority of cocaine users in our laboratory indicate that binges may last for days, with intervals of heavy cocaine use separated by brief breaks in which the user hustles in order to get enough money to buy more cocaine". Similarly, Cohen and Sas (1994) studied patterns of cocaine use in addicts in Amsterdam, and they report that sustained and high levels of use are "rarely maintained" and that "Many users lace their cocaine use career with periods of abstention. Such periods may last from a week to several months." This suggests that cocaine addicts are unlikely to maintain continuously high brain levels of drug over extended periods. Addicts do engage in drug binges, where drug is taken at a high frequency during a bout lasting from hours to days. For instance, craving for cocaine is reported to be highest shortly after intake of the drug (Jaffe et al., 1989 and O'Brien et al., 1992). This can favour the transition towards a binge pattern of administration and addiction (Gawin, 1991). However, even within a binge, the pattern of use appears to be intermittent. A recent study on this issue suggests that experienced users wait, on average, well over an hour between cocaine uses within a binge (Beveridge et al., 2012). Cocaine has a half-life of $\sim 40 \mathrm{~min}$ (Javaid et al., 1983). This suggests that during a binge, blood levels of the drug are not maintained at continuously high levels but might rise and fall in a spiking pattern (Zimmer et al., 2012). This intermittent and spiking pattern of drug levels is thought to promote the transition to cocaine addiction (Zimmer et al., 2012). Similarly, smoking cigarettes is also thought to be particularly addictive because the puff-by-puff inhalation of cigarette smoke produces intermittent and fast-rising spikes in brain levels of nicotine (Russell and Feyerabend, 1978) and of other components of tobacco smoke thought to enhance the addictive properties of nicotine (Berlin and Anthenelli, 2001).

\section{Preclinical studies show that drug pharmacokinetics determine brain and behaviour effects relevant to addiction} Clinical studies point to the very important role of pharmacokinetic variables in drug addiction liability-in particular the rapidity of drug onset and the intermittency of 
drug exposure. The clinical data are correlational, but they make clear predictions that can be tested empirically in animals. Animal studies provide greater opportunities to study how pharmacokinetic variables influence the response to drugs. Here we review evidence from such studies indicating the powerful influence of pharmacokinetic variables on drug effects relevant to addiction. We begin by presenting simpler models, in which pharmacokinetic variables are limited to dose and route of administration. We then lead through to selfadministration studies, where there are challenging interactions to be considered.

Until recently, the great majority of animal studies on the response to drugs used experimenter-administered, i.p. injections, and much has been learned from these experiments. Fig. 2 illustrates the pharmacokinetic profiles of an i.p. versus an i.v. injection of cocaine. Comparing Fig. 1 and Fig. 2 suggests that an i.p. injection produces a pharmacokinetic profile closest to that produced by intranasal or oral drug administration in humans. Though drug absorption is slower from the i.p. cavity, a vast literature shows that i.p. drug injections are nonetheless powerful in producing behavioural and neurobiological effects. This literature also highlights the importance of intermittent drug exposure followed by a withdrawal period in promoting sensitization-like changes in brain and behaviour (Vezina et al., 2007). Thus, studies using i.p. drug injections laid the groundwork for understanding how the temporal pattern of drug exposure influences the response to drug. For instance, intermittent exposure to drug achieved via experimenter-administered i.p. injections of cocaine (Downs and Eddy, 1932, Post, 1980, Post and Rose, 1976, Reith et al., 1987 and Stewart and Badiani, 1993) or nicotine (Baker et al., 2013 and Di Chiara, 2000) more readily induces sensitization to the psychomotor activating effect of these drugs, while continuous infusion produces tolerance to this effect.

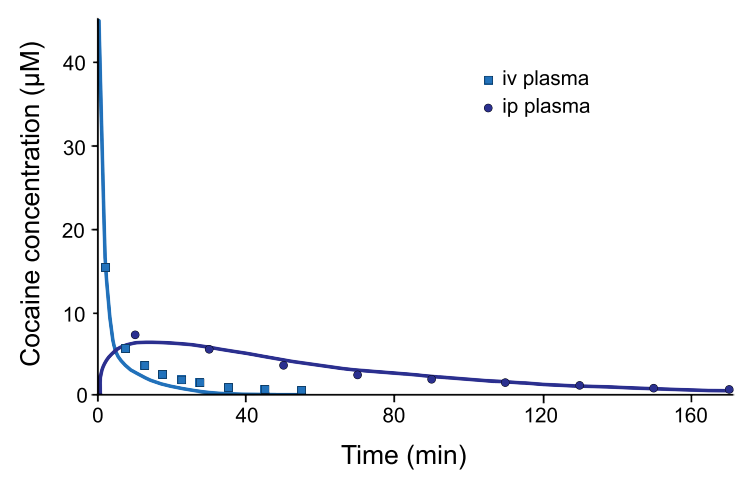

Fig. 2. The pharmacokinetic profiles of plasma cocaine levels in rats following intravenous (i.v.) and intraperitoneal (i.p.) administration. Plasma cocaine levels rise sharply and decline rapidly following an intravenous injection. In contrast, plasma cocaine levels rise and decline more slowly following an intraperitoneal injection of the drug. Note that following intravenous injection, cocaine concentrations in plasma rise rapidly and reach Cmax within the first 5 min, which was the earliest sampling interval in this experiment. Adapted from Pan et al. (1991).
Psychomotor sensitization refers to a gradual and progressive increase in the locomotor response to the same or lower doses of a drug with repeated treatment (Eikelboom and Stewart, 1982, Kuczenski and Segal, 1988, Robinson and Becker, 1986 and Siegel, 1977), and is also characterized by a faster onset of locomotor activation in response to drug administration (Carey and Gui, 1998 and Segal et al., 1981). The ability of drugs to produce psychomotor sensitization might reflect their ability to sensitize reward and motivational processes, thus promoting drug use and addiction (Robinson and Berridge, 1993, Robinson and Berridge, 2000 and Vezina, 2004). For instance, intermittent i.p. injections of amphetamine, morphine, or cocaine produce sensitization to the rewarding effects of these drugs, as measured by the conditioned place preference test (Lett, 1989). Intermittent i.p. injections of amphetamine, cocaine or nicotine also increase the susceptibility to subsequently initiate voluntary selfadministration of these drugs (Horger et al., 1990, Neugebauer et al., 2014, Piazza et al., 1990, Pierre and Vezina, 1997 and Pierre and Vezina, 1998) and increase the work output animals will emit to obtain drug (Mendrek et al., 1998, Neugebauer et al., 2014 and Vezina et al., 2002).

The intermittency of drug exposure also determines the nature and direction of cocaine-evoked neuroadaptations within the dopamine system- $\mathrm{a}$ system that is fundamental to the reinforcing effects of psychostimulant drugs. Intermittent, once a day i.p. cocaine injections enhance cocaine-induced inhibition of striatal dopamine reuptake (Izenwasser and Cox, 1990), while continuous infusion of the drug over a 24-h period attenuates the effects of cocaine on reuptake (Izenwasser and Cox, 1992). Intermittent cocaine administration also produces functional subsensitivity of D2 autoreceptors that modulate dopamine release, while continuous cocaine administration produces D2 autoreceptor supersensitivity (Jones et al., 1996). Within an intermittent, i.p. dosing schedule, the time interval between injections is also important. For instance, even when the total daily dose of cocaine is held constant, injecting the drug at short intervals preferentially evokes dopamine receptor upregulation within cortical and striatal brain regions (Unterwald et al., 2001). This suggests that the frequency of drug-evoked changes in extracellular dopamine levels, and by implication, the frequency of dopamine receptor activation, determines the long-term consequences of cocaine exposure (Unterwald et al., 2001).

Another model used to study drug effects relevant to addiction is the conditioned place preference paradigm. It measures the conditioned reinforcing properties of a physical environment that has been paired with the effects of a drug. In this paradigm, dose is generally the only pharmacokinetic variable studied (and this work shows that the ability of drugs like cocaine to produce a conditioned place preference is dose-dependent; Spyraki et al., 1982). A notable exception is work done by Nomikos and Spyraki. They compared the i.v. and i.p. routes and report that across a range of doses, conditioned place preference to i.v. cocaine requires fewer conditioning sessions, 
is less susceptible to procedural factors, and is of greater magnitude than conditioning with i.p. cocaine (Nomikos and Spyraki, 1988). The same group also reports that the dopamine D2/3 antagonist haloperidol disrupts conditioned place preference evoked by i.v. but not i.p. cocaine (Spyraki et al., 1987). This was one of the first findings to suggest that the neurobiology mediating the reinforcing effects of cocaine varies as a function of the route of drug administration. The speed of drug onset differs markedly when cocaine is injected i.p. versus i.v. (Fig. 2). Thus, the work of Spyraki and colleagues recalls what the clinical literature has taught; the speed of drug onset is critical in determining outcome.

The i.p. route cannot be used to manipulate the speed of drug onset; however, the i.v. route can. In a series of studies in rats, we have used experimenter-administered i.v. drug injections to study the effects of variation in the speed of drug onset on the susceptibility to develop psychomotor sensitization. The findings concord with the clinical literature. They show that the speed of drug onset determines behavioural plasticity. These studies using experimenter-administered i.v. injections of cocaine are also important in that they bridge the gap between the literature using i.p. drug injections (the great majority of the work on psychomotor sensitization and conditioned place preference) and the literature using animal models of i.v. drug self-administration. In these studies, we varied the speed of drug onset by varying the speed of i.v. injection between 3 and $100 \mathrm{~s}$. Across this range, there is no effect of injection speed on the acute locomotor response to cocaine or nicotine (Samaha et al., 2002, Samaha et al., 2004 and Samaha et al., 2005). However, we found that increasing the speed of cocaine or nicotine delivery by as little as $20 \mathrm{~s}$ increases the susceptibility to psychomotor sensitization (Samaha et al., 2002, Samaha et al., 2004 and Samaha et al., 2005). A first series of experiments showed that across a range of doses $(0.5-2 \mathrm{mg} / \mathrm{kg} /$ infusion $)$, and using both rotational behaviour in rats with a unilateral 6hydroxydopamine lesion (a manipulation which destroys nigrostriatal dopamine neurons) and locomotor activity in neurologically intact rats as indices of psychomotor activation, rapid i.v. injections of cocaine (3-16 versus $25-100$ s) promote the development of psychomotor sensitization (Samaha et al., 2002). Next, we showed that psychomotor sensitization to a single i.v. injection of cocaine developed when cocaine was injected rapidly (over $5 \mathrm{~s}$ ) but not when it was injected more slowly (25-100 s; Samaha et al., 2004). Fig. 3 illustrates this effect. Finally, we showed that the influence of the speed of drug onset also extends to another drug, nicotine. Rapid (5 versus $25-100$ s) i.v. injection also promoted the development of psychomotor sensitization to nicotine (Samaha et al., 2005). Of course, most studies of psychomotor sensitization use i.p. injections of psychostimulant drugs. Intraperitoneal injection would result in slower drug absorption relative to a 5 -s i.v. injection (Fig. 2), but it is nonetheless effective in producing psychomotor sensitization. Consistent with this, we found that slower i.v. drug injections can still produce sensitization but this requires the use of higher doses and repeated exposure (Samaha et al., 2002, Samaha et al., 2004 and Samaha et al.,
2005). Thus, the faster cocaine or nicotine are administered, the more likely they are to induce behavioural sensitization. A clear implication is that even when the route of drug administration is held constant, the speed of drug delivery must influence the effects of drugs on the brain.
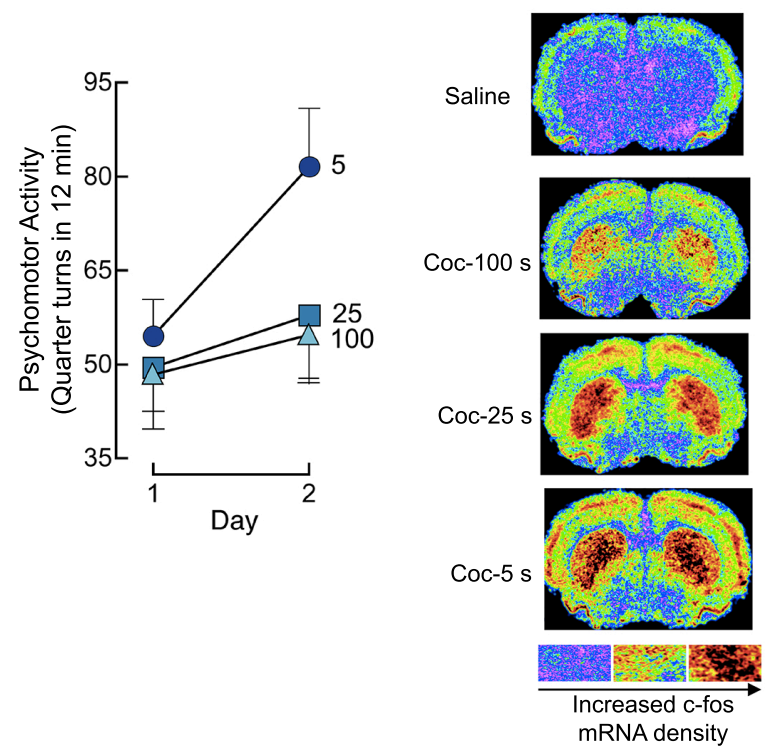

Fig. 3. Increasing the speed of intravenous cocaine delivery facilitates the development of psychomotor sensitization and promotes c-fos mRNA expression in corticolimbic regions. The panel on the left illustrates psychomotor activity averaged over the first $12 \mathrm{~min}$ following an intravenous injection of $2.0 \mathrm{mg} / \mathrm{kg}$ cocaine, delivered by an experimenter over 5, 25 or $100 \mathrm{~s}$, on two consecutive days. Data are mean \pm SEM. Panels on the right show representative densitograms illustrating c-fos mRNA levels in the brains of rats injected with $2.0 \mathrm{mg} / \mathrm{kg}$ cocaine at different speeds. Coc, cocaine. s, second. Adapted from Samaha et al. (2004).

Small variations in the speed of cocaine or nicotine onset have large effects on the neurobiological impact of these drugs. Increasing the speed of drug onset promotes changes in cellular activity in mesocorticolimbic structures (Porrino, 1993, Samaha et al., 2004 and Samaha et al., 2005; see Fig. 3), greater and more immediate increases in heat-producing, metabolic activity in the ventral tegmental area and nucleus accumbens (Brown and Kiyatkin, 2005), and more immediate increases in dopamine transporter blockade (Samaha et al., 2004) and extracellular dopamine levels (Ferrario et al., 2008) in the striatum. With the exception of Porrino (1993), who compared i.p. and i.v. injections of cocaine, the speed of drug onset was varied by manipulating the speed of i.v. drug injection between 4 and $100 \mathrm{~s}$. Pharmacokinetic modelling predicts that across these i.v. injection speeds, peak brain concentrations of cocaine would not vary, but the rate of rise of brain drug levels would (Samaha et al., 2002). Consistent with this prediction, this range of injection speeds produces differences in the rate of rise of striatal dopamine levels, without affecting peak dopamine overflow (Ferrario et al., 2008 and Zernig, 1997). Similarly, Woolverton and Wang (2004) manipulated the speed of i.v. cocaine delivery across an even wider range (10-600 s) and found that faster i.v. cocaine 
injections produce a more rapid onset of dopamine transporter occupancy without altering maximum occupancy levels. These findings agree with clinical work suggesting that across a range of cocaine doses that produce similar plasma levels of drug, i.v., smoked or intranasal cocaine produce the same maximum levels of dopamine transporter occupancy, while producing different subjective effects (Volkow et al., 2000).

\subsection{The effects of pharmacokinetic variables in intravenous drug self-administration models}

As a model of drug-taking behaviour, i.v. drug selfadministration in laboratory animals provides a strong opportunity to study how dose, speed of drug onset and intermittency of drug exposure interact to determine patterns of drug use. However, the model also offers considerable challenges. The pharmacokinetic issues can become quite complicated. Rather than dealing with a single, isolated injection, self-administration procedures result in multiple infusions, at various time intervals. The pattern of drug taking is influenced by summated brain levels, as well as how fast and how often these levels rise and fall. Understanding how pharmacokinetic variables affect cocaine intake and how cumulative cocaine exposure and the kinetics of this exposure affect cocaine seeking is critical to the design of animal models used in the study of the addiction process.

\subsection{Drug taking (consummatory) versus drug seeking (appetitive) responses}

Drug taking and drug seeking responses represent different categories of behaviour (i.e., consummatory and appetitive) that are likely regulated by different neural mechanisms (Roberts et al., 2013). Nonetheless, the sections below highlight that pharmacokinetic variables have parallel effects on the two response categories. The difference between appetitive and consummatory responses is rather obvious in humans; the consummatory response (smoking, drinking/swallowing, injecting, snorting) is an ingestive act that can become ritualistic. Appetitive responses involve more varied behaviours that result in gaining access to the drug (acquiring money, seeking out suppliers, paying for drug). Similarly in a typical operant experiment in which food is used as reinforcement, a lever response or nose poke would be considered an appetitive response that results, according to a defined schedule, in the delivery of a food pellet. The animal then has the option of ingesting the food. Pressing a lever and eating a food pellet are clearly different response types representing the appetitive and consummatory class. This distinction is also important in that it shapes experimental questions. For instance, identifying the processes an individual might use to regulate their intake of free alcohol is quite different from determining how much someone might pay for a particular bottle of wine.

In experiments involving animals self-administering drug via i.v. catheters, consummatory and appetitive responses are not as clearly partitioned. As discussed elsewhere, intravenous drug self-administration studies - particularly under a fixed ratio 1 schedule of reinforcement (one operant response provides one drug infusion; FR1) - are a special case wherein the appetitive and consummatory responses are in fact necessarily conflated (Roberts et al., 2013). Since drug reinforcement is a programmed infusion delivered via a catheter, the consummatory act is entirely circumvented; there is no external stimulus to direct an ingestive behaviour towards (no smoking, drinking/swallowing, injecting, snorting). The nose poke or lever press becomes not only an appetitive response in the traditional operant sense but also a consummatory response that controls drug ingestion.

Whether the rates and patterns of responding exhibited in an intravenous drug self-administration experiment are controlled by appetitive or consummatory mechanisms will depend, to a large extent, on the schedule of reinforcement used. When using an FR1 schedule, every response leads to the intake of drug, thus every response is a consummatory act (though in light of the discussion above, the response might also reflect an appetitive process). An FR1 schedule therefore provides an opportunity to study the mechanisms that control drug intake. Such studies can presumably model specific human drug taking patterns and therefore allow the opportunity to study phenomena associated with limited versus extended drug access and "binges" for example. Below we will discuss how dose, speed of injection and intermittency of access affect the rates and patterns of cocaine consumption. Finally, we will discuss how these same pharmacokinetic variables influence appetitive responding, as measured using schedules that require an exponential increase in work demand in order to obtain each successive reinforcer, thus producing higher rates of operant behaviour prior to the delivery of the drug, in particular the progressive ratio schedule of drug reinforcement (PR). It could well be argued that FR schedules above FR1 also measure appetitive responses because they require that several operant responses be emitted before delivery of the reinforcer. However, this raises the difficult question of how many operant responses under an FR schedule are required to convincingly tap into appetitive processes. For example, it is not clear whether an FR2 schedule measures a psychological process different from that measured by FR1. In contrast, responses under a PR schedule of reinforcement are unequivocally appetitive. Another important difference between a PR schedule and an FR1 schedule is that a PR schedule produces very high work demand. Under a PR schedule, obtaining each successive drug injection requires an increasing number of operant responses, until the subject ceases drug selfadministration. The number of operant responses performed to obtain the last drug infusion is termed the breakpoint and it is used to infer the motivation to obtain drug (Hodos, 1961 and Richardson and Roberts, 1996). Thus, the PR schedule queries an animal about how much physical work it is willing to emit to obtain a reinforcer, and the answer is used as an index of the motivation to procure that reinforcer. Schedules such as PR lend themselves to standard operant interpretation and can be used to assess motivational issues under conditions of very high work demand (Roberts et al., 2013). Such schedules can be used with operant theory or behavioural 
economics to infer changes in the motivation to seek drugs or continue a binge.

A substantial body of evidence has accumulated which shows that drug consumption and appetitive responding for drugs have partially distinct neurobiological substrates and are differentially affected by a wide variety of manipulations. For example, drug consumption under conditions of very low work demand (under an FR1 schedule) and appetitive responding for drugs under conditions of high work demand (under a PR schedule) are differentially affected by neurotoxic lesions (Loh and Roberts, 1990, Roberts, 1989 and Roberts et al., 1994), pharmacological pretreatments (Brebner et al., 2000 and Espana et al., 2010), the estrous cycle (Roberts et al., 1989) and diurnal rhythms (Bass et al., 2010 and Fitch and Roberts, 1993). Note that while human addicts do not selfadminister drug on PR schedules per se, they are willing to suffer significant escalations in both price and work output in order to obtain drug. In addition, PR tests in animal models are essential because they provide tools to assess how various patterns of drug taking influence the motivation for further use. In the following sections, we will use the rough distinction between FR1 schedules of reinforcement versus other schedules with higher response requirements such as the PR procedure to discuss the effect of pharmacokinetic variables on drug taking versus drug seeking, respectively.

\subsection{Pharmacokinetic variables influence drug-taking (consummatory) behaviour}

\subsubsection{Drug-taking behaviour during limited daily access to drug}

Pharmacokinetic variables such as dose and speed of drug onset have minor effects on rate of drug intake in the acute stagebut in situations that would be expected to promote a change in the pattern of intake, these variables are critical. First, it is important to recognize that cocaine self-administration can be remarkably stable. Although drug self-administration during daily 1-3 h, FR1 sessions can produce psychomotor and neurochemical sensitization, and sensitization-related neuroadaptations can promote increased drug intake (Hooks et al., 1994, Lorrain et al., 2000 and Phillips and Di Ciano, 1996), cocaine intake during short daily sessions is tightly regulated and changes little over time (Ahmed et al., 2002, Ahmed and Koob, 1998, Deroche-Gamonet et al., 2004, Knackstedt and Kalivas, 2007 and Mantsch et al., 2004). Under these stable conditions, manipulations of dose generally have little effect on intake within or between sessions. For instance, if cocaine dose is manipulated during limited FR1 self-administration sessions, rats will self-administer lower doses more frequently than higher doses (Pickens and Thompson, 1968 and Wilson et al., 1971), but hourly intake will typically remain stable both within a session and over days. Fig. 4 shows the cocaine doseresponse relationship under these conditions, depicted as the responses during a $2-\mathrm{h}$ session. The figure illustrates that cocaine intake is held constant across a 10-fold range of doses (41-421 $\mathrm{g}$ /infusion). Fig. 5a shows fluctuations in brain cocaine levels in an animal self-administering $500 \mu \mathrm{g} /$ infusion under these conditions, estimated using a mathematical model (Ahmed and Koob, 2005, Nicola and Deadwyler, 2000, Pan et al., 1991 and Wise et al., 1995). The event record in Fig. 5a shows that there is a typical "loading phase" at the beginning of the session - a collection of several injections that produce a rapid rise in brain levels followed by an extremely regular pattern of responding that results in brain cocaine levels being maintained within a narrow range. Under these conditions, both hourly cocaine intake and intake over days remain relatively constant across a wide dose range. It is not clear why intake under these conditions generally does not change over time, or why some conditions that can produce psychomotor and neurochemical sensitization produce unchanging levels of drug intake. Just as the expression of behavioural sensitization is observed more readily following a period of drug withdrawal, it is possible that following limited daily self-administration sessions, an increase in drug intake might be observed after a sufficiently long abstinence period. However, it has been shown that in animals with a history of self-administering cocaine during short daily sessions, drug intake remains stable even following one month of forced abstinence (Ahmed and Koob, 1998 and Hollander and Carelli, 2005). Thus, escalation of drug intake is often not observed following short daily selfadministration sessions, even though the same conditions can evoke psychomotor and neurochemical sensitization. Based on such evidence, some authors have concluded that psychomotor sensitization should not be used as a marker for the transition to increased drug use (Ahmed and Cador, 2006), while others maintain that psychomotor sensitization and changes in drug use are more readily linked under conditions of extended access to drug (Ferrario et al., 2005).
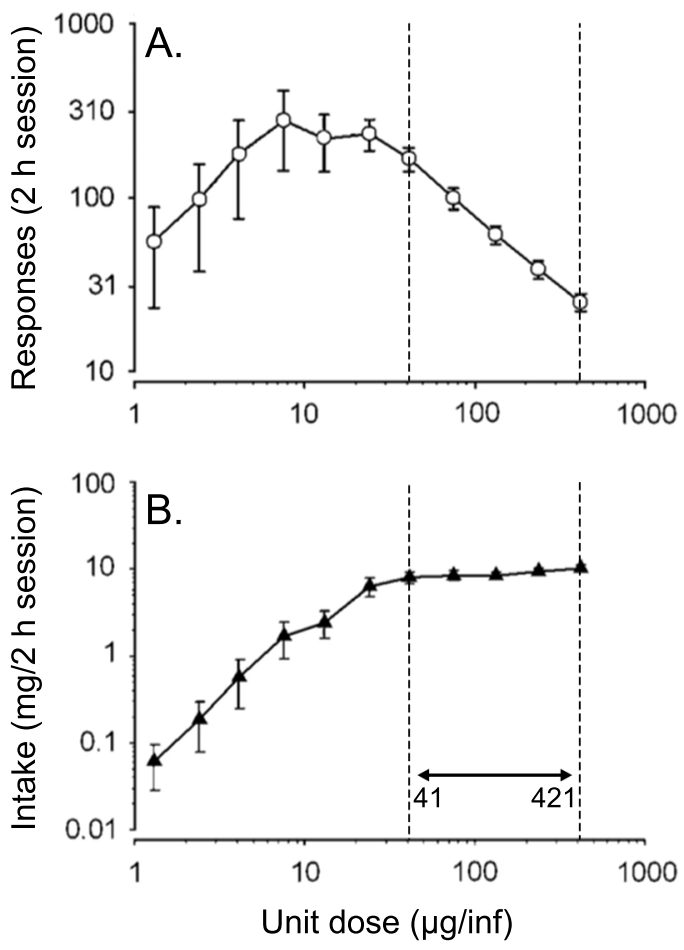

Fig. 4. The effect of manipulating dose on rate of responding (A) and total intake (B) for a group of rats self-administering intravenous 
injections of various unit doses of cocaine during daily two-hour sessions. Panel A illustrates an inverted ' $U$ ' shaped curve, and at the high end of this curve, responding decreases as dose increases. Panel $B$ illustrates that over the dose range characterized by a decrease in the number of injections (41-421 $\mu \mathrm{g} /$ infusion, framed within dotted lines), intake is relatively constant. Data are mean \pm SEM. Adapted from Oleson and Roberts (2009).

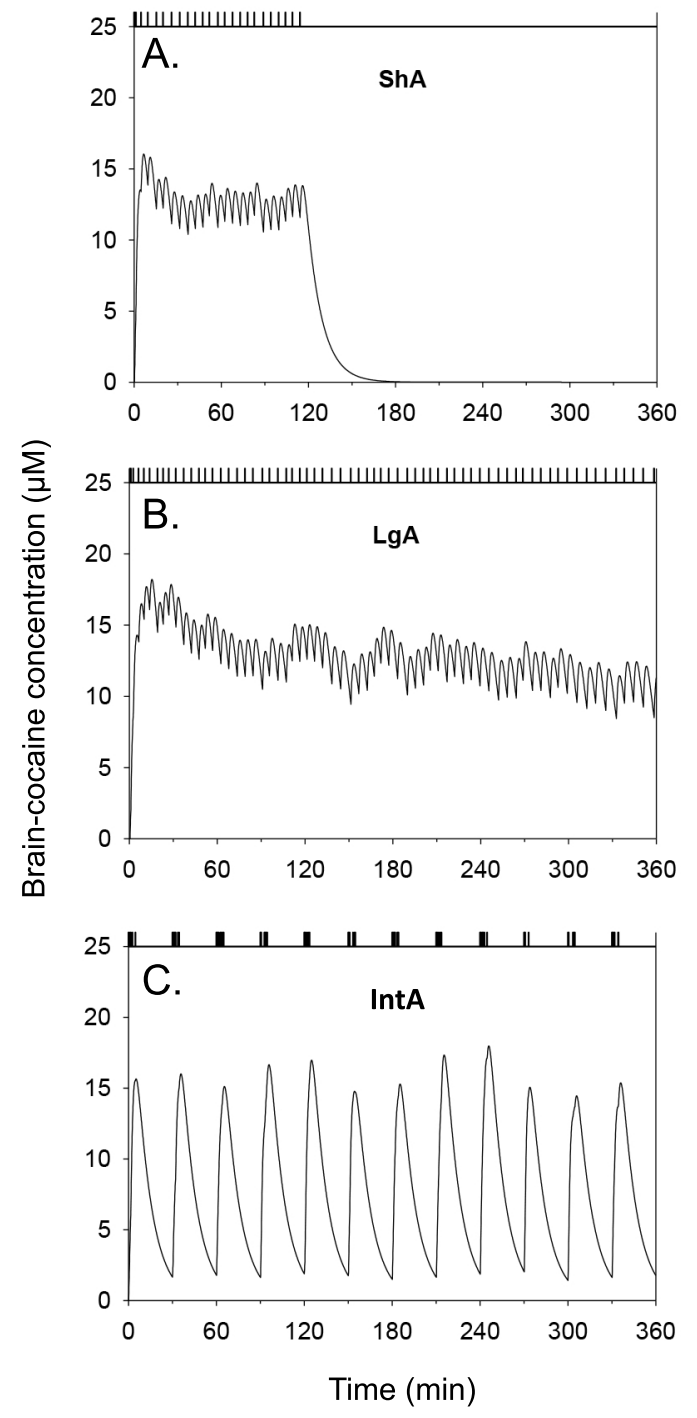

Fig. 5. The pattern of intake and modelled cocaine levels in the brain for representative animals tested during three distinct selfadministration procedures. Each panel shows the modelled brain levels of cocaine corresponding to the pattern of intake indicated by the event record. Curves were generated using a model developed by Pan et al. (1991). Pan et al. (1991) used microdialysis to measure brain concentrations of cocaine injected intravenously. The relevant pharmacokinetic parameters were then estimated by fitting a twocompartment open model to the data using nonlinear regression. The equations used by the model and the parameter estimates are provided in Pan et al. (1991). ShA, 2-h, Short Access session $(0.75 \mathrm{mg} / \mathrm{kg} /$ infusion, with a 20 -s time out period). LgA, 6-h, Long Access session $(0.75 \mathrm{mg} / \mathrm{kg} /$ infusion, with a 20 -s time out period). IntA, 6-h, Intermittent Access session (12 discrete 5-min trials separated by a 25 -min inter-trial-interval; $0.375 \mathrm{mg} / \mathrm{kg} /$ infusion). Note that in the intermittent access sessions, no time out was imposed, allowing animals to self-administer multiple injections within a few seconds. Adapted from Zimmer et al. (2012).
During time-limited (1-3 h), FR1 sessions, the speed of drug delivery has minor effects on drug intake acutely, but it can significantly influence change in drug use over time. Some studies show that rapid i.v. injections of cocaine or nicotine lead to greater drug intake within each time-limited session (Kato et al., 1987, Schindler et al., 2011 and Schindler et al., 2009), other studies do not show this effect (Crombag et al., 2008, Minogianis et al., 2013, Sorge and Clarke, 2009 and Wakabayashi et al., 2010). This suggested that the speed of drug onset might not critically influence drug intake during short, FR1 sessions. However, a more recent study suggests that this lack of effect might be restricted to the initial stages of drug self-administration (the first 3-4 sessions following acquisition of the drug self-administration task). Bouayad-Gervais et al. (2014) showed that, consistent with prior studies (Crombag et al., 2008, Minogianis et al., 2013 and Wakabayashi et al., 2010), varying the speed of i.v. cocaine injection ( 5 or $90 \mathrm{~s}$ ) has no effect on intake during the first 3-4 self-administration sessions. However, BouayadGervais et al. (2014) bring new data to this literature by showing that beyond these initial sessions, faster i.v. cocaine injections led to greater drug intake than slower cocaine injections. Group differences emerged because the rats given access to slower cocaine injections decreased their intake over days. In contrast, the rats given access to more rapid injections maintained stable drug intake over test days. The latter finding is consistent with the great majority of studies using short daily self-administration sessions $(1-3 \mathrm{~h})$, where drug is delivered at speeds comparable to $5 \mathrm{~s}$, and intake remains stable over time. It remains to be determined why the self-administration of sustained cocaine infusions decreases over repeated test days. As research on this issue unfolds, the findings of BouayadGervais et al. (2014) support the idea that variation in the speed of drug delivery evokes neuroadaptations over time, leading to differences in drug intake with repeated drug exposure. The next section will show that the effect of pharmacokinetic variables including the speed of drug onset on drug intake over days is even more dramatic in animals given longer daily sessions (long-access sessions; $\operatorname{LgA}$ ) - a procedure designed to promote addiction-related neuroplasticity.

\subsubsection{Drug-taking behaviour during extended daily access to drug}

"Escalation of drug intake" has become a major focus in the cocaine self-administration literature and this phenomenon also serves to illustrate the importance of pharmacokinetic variables in behavioural plasticity. Here we will show that the capacity for one day of cocaine intake to influence the rate of intake on the next day is facilitated by the use of large doses, intermittent drug access, and doses injected quickly. Lengthening the daily session length, a procedure termed long access ( $\operatorname{LgA})$, has been shown to increase the rate of within-session intake by about 40-70\% over 2-3 weeks (Ahmed and Koob, 1998, Ahmed and Koob, 1999, Ben-Shahar et al., 2004, Knackstedt and Kalivas, 2007 and Wee et al., 2008). The LgA procedure is a powerful animal model because if one wishes to model addiction in laboratory animals, one expects these animals to change their 
drug-taking behaviour over time. In the LgA model, escalation of drug intake is modulated by several variables. For instance, rats can show significant inter-individual variability in the propensity to escalate their cocaine intake (Deroche-Gamonet et al., 2004 and Wakabayashi et al., 2010). Pharmacokinetic variables also play a role. For instance, using nicotine, it has been shown that when periods of drug self-administration are interspersed with periods of forced abstinence, this promotes an escalation in nicotine intake (Cohen et al., 2012). Furthermore, escalation might be more likely at high doses of cocaine. Doseresponse curves are not widely studied in the literature on the escalation of cocaine intake. A notable exception is Mantsch et al. (2004), who showed that escalation occurs earlier at higher doses (2 versus $0.5 \mathrm{mg} / \mathrm{kg} /$ injection). This is in line with a number of studies that have failed to see escalation of cocaine intake at lower drug doses $(0.25-0.6 \mathrm{mg} / \mathrm{kg} /$ injection) (Ferrario and Robinson, 2007, Kippin et al., 2006, Mantsch et al., 2004 and Minogianis et al., 2013). Escalation is also facilitated by a rapid speed of cocaine onset. Studies showing that prolonged daily access to drug can promote the escalation of drug intake use rapid i.v. injections of drug (Ahmed and Koob, 1998, Ahmed and Koob, 1999, Ben-Shahar et al., 2004, Knackstedt and Kalivas, 2007 and Wee et al., 2008). This prompted us and others to ask whether the speed of drug delivery plays a role in the propensity to escalate drug consumption. Work on this issue showed that when daily access to cocaine is increased from 1 to $6 \mathrm{~h}$, rats given access to rapid (5-45 s) versus slower $(90 \mathrm{~s})$ injections of cocaine take more drug and are also more likely to escalate their consumption over days (Bouayad-Gervais et al., 2014, Minogianis et al., 2013 and Wakabayashi et al., 2010). Fig. 6 illustrates this effect. Such effects are observed in spite of the fact that in these latter studies, all rats had equal opportunity to take cocaine (one injection was available every $90 \mathrm{~s}$ ). Thus, extended access to drug by itself is not sufficient to promote escalated drug use, and the speed of drug onset is decisive in producing this behavioural change. In summary, in agreement with clinical observations and the literature on psychomotor sensitization, dose, the intermittency of drug use, and the speed of drug onset are key determinants of behavioural change in the LgA model of drug self-administration. This serves to highlight the role of pharmacokinetic factors in the plastic changes associated with the addiction process.

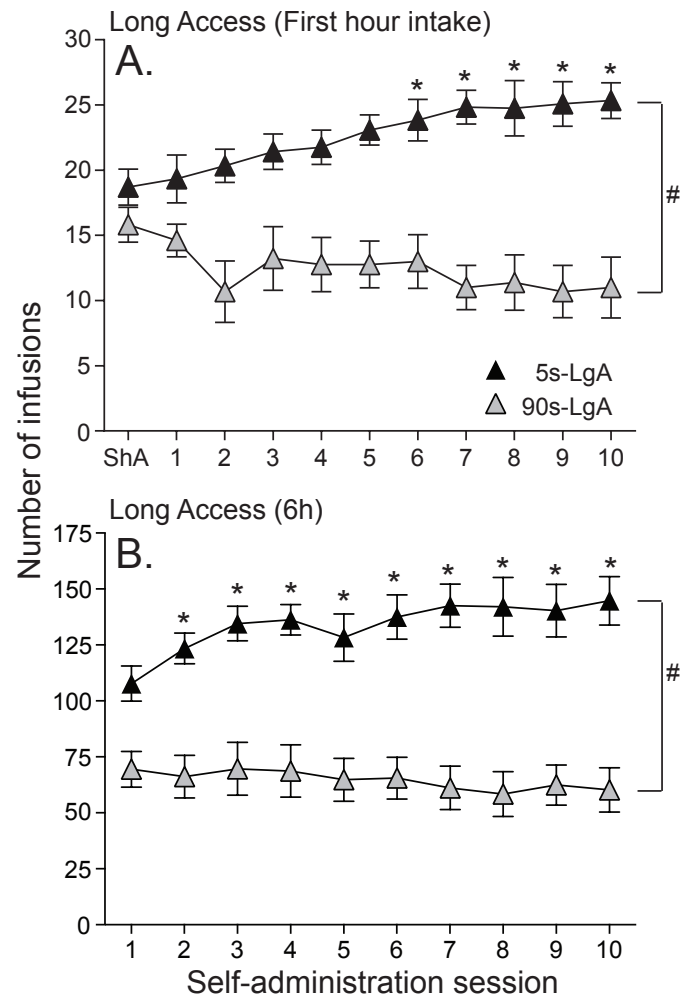

Fig. 6. In rats given extended daily access to cocaine, only those selfadministering rapid cocaine injections escalate their drug intake over time. Panel A shows cocaine intake in the first hour of the 6-h session, in rats self-administering rapid intravenous cocaine injections (delivered over $5 \mathrm{~s}$ ) and in rats self-administering slower injections (90 s). Panel B shows total cocaine intake during each 6-h session in the same animals. Rats received three short-access sessions (ShA; $1 \mathrm{~h}$ /session) prior to the 10 long-access sessions ( $\mathrm{LgA} ; 6 \mathrm{~h} /$ session). In (A), 'ShA' shows the average number of infusions taken over these three sessions. Data represent mean \pm SEM. $N=12-13$ /group. $\mathrm{s}$, second. $\# \mathrm{p}<0.05$ compared to the 90 -s rats. $* \mathrm{p}<0.05$ compared to the 1 st session of LgA in 5-s rats. Adapted from Bouayad-Gervais et al. (2014).

\subsection{Pharmacokinetic variables influence drug-seeking (appetitive) behaviour}

A key question in addiction is how specific patterns of drug taking predispose an individual to further drug use. This is a critical question to address if one wishes to understand why some drug users maintain control over their drug use, while others develop excessive and pathological patterns of drug use, and ultimately addiction. Accordingly, there is now a trend in the literature to assess how cocaine consumption affects the appetitive response - or put another way - how patterns of consumption subsequently affect an animal's motivation to seek and use drugs. In the next sections, we will review some procedures that affect appetitive responding for drug. These include the long access $(\operatorname{LgA})$, discrete trials (DT), and progressive ratio training (PR) procedures. Data from these models hint at the importance of the intermittency of drug use and speed of drug onset in determining the subsequent motivation to seek and take drug. Finally, we will review findings from a new model of drug self-administration behaviour that powerfully illustrates how intermittent 'spikes' 
in brain levels of cocaine can be more effective than high and sustained levels in determining the subsequent motivation to seek and take the drug.

\subsubsection{The long-access model}

While some inconsistencies exist, there are numerous reports of drug self-administration under LgA conditions changing the susceptibility to relapse, drug seeking in spite of punishment, and, responding for drug under a PR schedule of reinforcement. For instance, compared to rats given limited daily access to cocaine, rats given $\operatorname{LgA}$ sessions are more vulnerable to drugprimed reinstatement of previously extinguished responding for cocaine (Ahmed and Cador, 2006, Ahmed and Koob, 1998, Knackstedt and Kalivas, 2007 and Mantsch et al., 2004). LgA rats also show greater responding for cocaine in spite of punishment (footshock) (Vanderschuren and Everitt, 2004), and also reach higher breakpoints for cocaine under progressive ratio conditions (Hao et al., 2010, Paterson and Markou, 2003 and Wee et al., 2008; note however that this latter effect is not always observed, Bouayad-Gervais et al., 2014, Liu et al., 2005a and Oleson and Roberts, 2009).

While testing of pharmacokinetic variables with the LgA model has been limited, the data again support the idea that intermittent drug access, high doses and a rapid speed of drug onset are critical to the ability of extended self-administration sessions to influence appetitive responding. The data further show that there are strong parallels in the effects of pharmacokinetic variables on consummatory and appetitive behaviours. For instance, when access to cocaine is given intermittently by interspersing $\operatorname{LgA}$ sessions with periods of forced abstinence, this promotes the development of increased motivation for cocaine, as assessed using a progressive ratio schedule of cocaine reinforcement (Morgan and Roberts, 2004). The ability of $\mathrm{LgA}$ sessions to promote cocaine-primed reinstatement of drug-seeking behaviour is also facilitated by the use of high doses during the LgA phase (Mantsch et al., 2004). Finally, when the speed of i.v. drug injection is varied during LgA sessions, rats allowed to self-administer rapid cocaine injections (5 versus $90 \mathrm{~s}$ ) subsequently show increased motivation to obtain the drug (Bouayad-Gervais et al., 2014 and Minogianis et al., 2013). This effect is illustrated in Fig. 7. Rats with a history of taking rapid cocaine injections are also more vulnerable to drug-primed reinstatement of cocaineseeking behaviour after a long period of forced abstinence (45 days; Wakabayashi et al., 2010). The ability of rapidly administered cocaine to increase motivation to obtain drug and the susceptibility to reinstatement is not just a consequence of the amount of drug previously consumed. Even when the rats self-administering rapid cocaine injections take the same amount as rats self-administering slower injections, the former show greater motivation for drug and a more persistent vulnerability to reinstatement (Bouayad-Gervais et al., 2014, Minogianis et al., 2013 and Wakabayashi et al., 2010). Thus, how much, how often and how fast a drug reaches the brain all determine the neuroplasticity that underlies changes in appetitive behaviours characteristic of addiction.

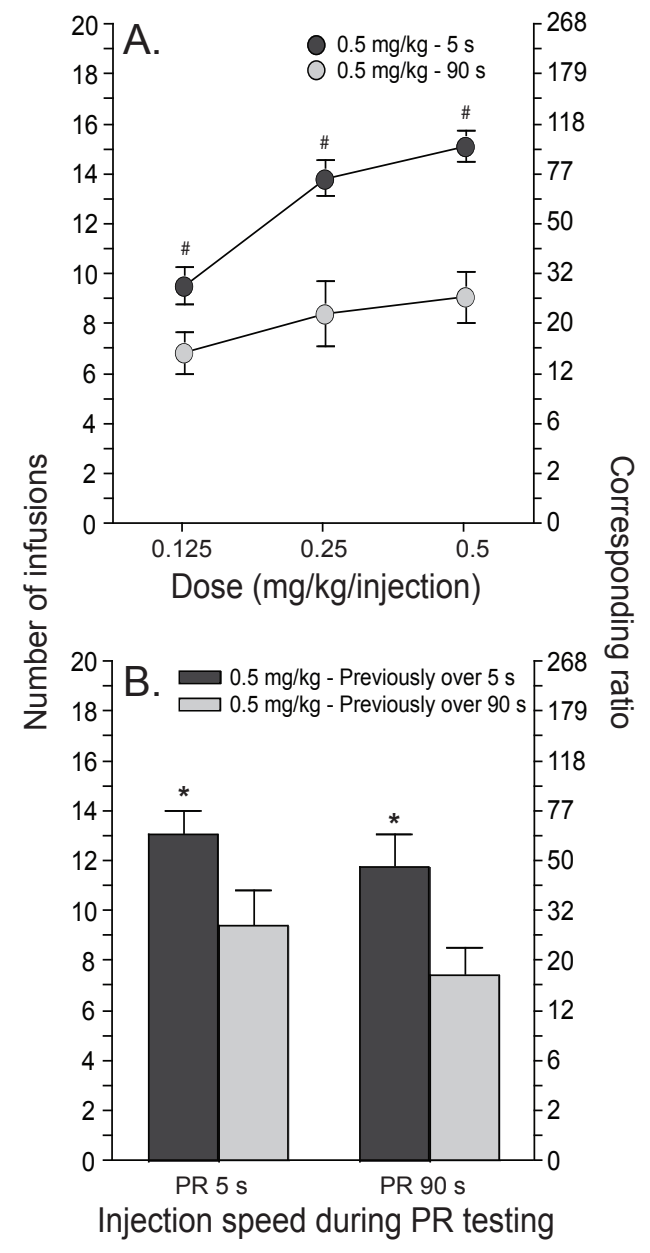

Fig. 7. The self-administration of rapid cocaine injections in the past leads to increased motivation to take the drug in the future. The figure illustrates responding for intravenous cocaine injections under a progressive ratio schedule of reinforcement in animals that have previously self-administered rapid (delivered over $5 \mathrm{~s}$ ) or more sustained ( $90 \mathrm{~s}$ ) cocaine infusions. Corresponding ratios are included. Panel A illustrates that rats in the 5-s group show an increased motivation to take cocaine, across a range of doses during progressive ratio testing. In (A), cocaine was delivered over $5 \mathrm{~s}$ for the 5 -s group, and over $90 \mathrm{~s}$ for the 90 -s group. Panel B shows that rats in the 5-s group also show an increased motivation to take cocaine regardless of drug injection speed during progressive ratio testing. Data represent mean \pm SEM. $\mathrm{N}=11-16$ /group. $\mathrm{s}$, second. PR $5 \mathrm{~s}$, cocaine was delivered over $5 \mathrm{~s}$ during progressive ratio testing. PR $90 \mathrm{~s}$, cocaine was delivered over $90 \mathrm{~s}$ during progressive ratio testing. $\# \mathrm{p}<0.0001$ and $* \mathrm{p}<0.05$ compared to the 90 -s rats. Adapted from Minogianis et al. (2013).

What accounts for the ability of $\operatorname{LgA}$ self-administration sessions to influence subsequent appetitive responding for drug? The early literature suggested that increased appetitive responding for drug results from elevated amounts of drug consumed (i.e., area under the curve). Some suggest the existence of " .... a threshold level that can readily establish and sustain addiction" (Benowitz and Henningfield, 1994), and that "...below this critical level of exposure, there would be no drug-induced neuropathological changes, and drug use would remain under control, at least in the majority of drug-exposed 
animals" (Ahmed, 2012). Said differently, to induce addiction, "more is better" and sustained levels are important. This is a reasonable assumption given that compared to ShA sessions, LgA sessions are much more effective in promoting future appetitive responding for drug, and an obvious difference between the two procedures is the level of prior drug exposure (modelled in Fig. 5). If this is correct, then elevated brain levels in the past should be sufficient to enhance the motivation to obtain drug in the future. Another possibility is that the number of injections is important. That is, that the frequency at which brain levels of drug rise and fall might influence future patterns of drug use. The fact that dose and speed of injection are critical factors suggests that the size and speed of the "spike" in cocaine levels may be important. However, it is difficult to test the relative contributions of area under the curve versus spiking brain levels in conventional $\mathrm{LgA} / \mathrm{ShA}$ models. The length of the session and the number of injections will always be confounded. Whether 'spikes' are necessary and/or sufficient to drive the important behavioural and neurochemical changes associated with the addiction process needs to be tested using different experimental procedures. As will be detailed further below, recent work tests this directly.

\subsubsection{The discrete trials model}

Discrete trials procedures (DT) were a first attempt in determining whether an increase in the motivation to obtain drug could be seen in animals with a history of intermittent rather than continuous drug access during each selfadministration session. The DT procedure allows animals to self-administer $24 \mathrm{~h}$ a day, but manipulates hourly drug intake. Animals have the opportunity to self-administer one injection and must then wait until the next trial within the hour for another opportunity. For example, DT4 involves giving 4 opportunities to take a single drug injection per hour. Under this schedule, rats tend to take an injection during every trial for the first $24 \mathrm{~h}$ and then settle into a regular daily pattern of intake, with drug taking restricted to the dark phase of the activity cycle (Roberts et al., 2002). Interestingly, selfadministration on a DT4 protocol for 10 days increases breakpoints under a PR schedule of reinforcement, and this increase depends on an abstinence period. If animals are tested immediately after 10 days of DT4 there are no changes in breakpoints (Morgan et al., 2002 and Morgan et al., 2005). But if a seven-day abstinence period is introduced, then sensitization of breakpoints is observed (Morgan and Roberts, 2004). The DT procedure thus illustrates that high and sustained brain levels of drug (as achieved with a conventional $\operatorname{LgA}$ session) are not a necessary condition to enhance the subsequent motivation for drug. The DT4 model also demonstrates that intermittent drug exposure followed by an abstinence period facilitates the development of sensitization to the motivational effects of cocaine. This concords with the literature on psychomotor sensitization, where intermittent drug exposure and a withdrawal period can be decisive (Downs and Eddy, 1932, Post, 1980, Post and Rose, 1976, Reith et al., 1987, Robinson and Becker, 1986 and Stewart and Badiani, 1993). The DT model does have its limits. It can be argued that the parameters are arbitrary and restrictive, and that the daily pattern does not resemble the way human addicts take cocaine. Still, it is an important demonstration that an intermittent pattern of cocaine intake evokes sensitization of appetitive responding for cocaine.

\subsubsection{Daily testing under a progressive ratio schedule of cocaine reinforcement}

Daily testing on a PR schedule of drug reinforcement is another procedure illustrating that sustained brain levels of drug are not a necessary condition to augment subsequent appetitive responding for drug. With daily testing, breakpoints maintained by cocaine escalate to very high levels over time (Liu et al., 2005b). Intriguingly, very low levels of prior cocaine intake result in rapid sensitization of breakpoints, whereas high levels of prior intake suppress the development of this sensitization (Morgan et al., 2006). Daily testing under a PR schedule of drug reinforcement was not intended as a model of human drug taking. However, the observation that breakpoints escalate over time - with about the same drug exposure as ShA - suggests that something interesting is going on. One possibility is that the schedule imposes a constraint on intake. It takes time to complete the high response ratios and brain levels of drug fall in between each injection. As such, the PR schedule would promote greater 'spiking' from lower brain levels of drug than the LgA procedure. Are these 'spikes' in brain drug levels important? Indeed they are. The susceptibility to escalate breakpoints for cocaine is determined by dose and the speed of drug onset (Liu et al., 2005b). When rats were given access to cocaine injections delivered i.v. over 5,25 or $50 \mathrm{~s}$, only rats taking 5-s injections showed an escalation in breakpoints. Similarly, only larger unit injection doses produced escalation of breakpoints (Liu et al., 2005b). These findings suggest that a rapid rise from low to high brain levels of drug is an important determinant of the future motivation to seek and take cocaine.

\subsubsection{A new model: Intermittent access to drug during a long- access session}

The protocols reviewed above suggest that rapidly rising and intermittent spikes in brain levels of cocaine might be decisive in predicting subsequent appetitive responding for drug, but this awaited formal investigation. Recently, one of the authors of the present review (D.C.S.R.) set about testing whether fast, "spiking" levels might drive the change in appetitive responding. To this end, a new model of cocaine selfadministration was developed involving intermittent, withinsession access to drug (Zimmer et al., 2012). The recent survey data in experienced cocaine users that we described above provided additional impetus to develop this model. These survey data suggested that experienced cocaine users likely do not maintain high brain levels of the drug, but might instead voluntarily achieve marked reductions in brain levels, which then rapidly rise with each drug self-administration (Beveridge et al., 2012). The intermittent access (IntA) procedure models this by limiting cocaine availability during a 6 -h session to twelve 5-min discrete trials separated by 25 -min timeout periods. Brain cocaine levels cannot be maintained; instead the 
animals experience twelve rapidly rising spikes in cocaine levels during each session. Thus the IntA protocol tests the effect of a history of cocaine 'spikes' on the motivation to selfadminister the drug later on, and it also allows for a direct test of the importance of 'spiking' versus sustained cocaine levels (Zimmer et al., 2012). To this end, IntA rats were compared to LgA rats. Predictably, the LgA group took much more cocaine than the IntA group. In addition, pharmacokinetic modelling suggested that LgA sessions would produce continuously high brain cocaine levels while IntA sessions would produce repeated, fast-rising spikes in brain cocaine levels (modelled in Fig. 5). Remarkably, in spite of being exposed to significantly less cocaine, the IntA rats were more motivated to selfadminister the drug in the future (Zimmer et al., 2012). This is consistent with other findings showing that even extremely high levels of cocaine intake are not sufficient on their own to increase the subsequent motivation to take the drug (Roberts et al., 2002). Such findings are a challenge to the belief that simply maintaining high levels of drug intake is sufficient to develop an addicted phenotype. Instead, it appears that when it comes to producing an increase in the motivation to obtain drug, 'how often' drug is taken can be more important than 'how much'. In support of this idea, recent work in rats shows that the early occurrence of a burst-like pattern of cocaine intake is a behavioural marker of vulnerability to compulsive drug use (Belin et al., 2009). Amongst a group of rats allowed to self-administer cocaine, the subset that spontaneously and rapidly developed a high-frequency pattern of intake (spontaneous intake of $>5$ infusions in less than $5 \mathrm{~min}$ ) was particularly vulnerable to develop addiction-like symptoms. These symptoms included increased motivation to obtain drug, persistence of drug-seeking behaviour in spite of signalled unavailability of cocaine and self-administration in spite of physical punishment. Importantly, the rats that developed a burst-like pattern of cocaine use did not differ from the other rats with respect to cumulative cocaine intake. Similarly, by dividing rats into two groups based on their spontaneous, selfimposed interval between cocaine infusions, Martin-Garcia et al. (2014) found that rats showing high-frequency cocaine selfadministration are more vulnerable to cocaine-primed reinstatement of drug-seeking behaviour relative to rats with low-frequency cocaine intake-in spite of equivalent levels of prior drug intake. Together, these findings suggest that an intermittent pattern of use, more than the amount of drug used, governs the susceptibility to increased drug use.

A key question is how the IntA procedure maps onto what we know about human cocaine intake. As discussed, new work suggests that experienced cocaine users take cocaine in a pattern different than previously thought, achieving intermittent and rapidly rising brain levels of the drug, rather than maintaining high and sustained levels (Beveridge et al., 2012). Even in between bouts of drug self-administration, human addicts likely do not have relatively continuous access to drug, several hours a day, for weeks/months on end (as modelled by the LgA procedure). Due to the interaction of several factors, some willed by the user, others not (jail time, lack of money, etc) drug intake, particularly cocaine intake, is intermittent, both within and between bouts of intoxication. Given this, understanding what happens to the brain when cocaine intake is intermittent is important. By modelling this in laboratory animals, the IntA procedure clearly shows that in producing change in the motivation to take drug over time, sustained brain levels of drug are not necessary, and spiking levels look to be the prime determinant. This is consistent with clinical observations, and also corroborated by evidence from studies using the more traditional LgA, DT and daily PR testing procedures, where a rapid speed of drug onset and high doses are critical for the development of behavioural change.

\subsection{Pharmacokinetics determine the neuroplasticity evoked by drugs}

Pharmacokinetic variables determine the impact drugs have on the brain. Everything that we have described for behaviour above has important parallels with neurochemical and neurobiological findings. A first series of studies showed that the speed of drug onset determines drug-induced effects on gene regulation. Rats with a history of taking rapid cocaine injections during LgA sessions show desensitization of cocaine-evoked Fos expression in the nucleus accumbens, while rats exposed to slower injections do not (Wakabayashi et al., 2010). This is reminiscent of findings using experimenteradministered nicotine, showing that rats that were previously treated with rapid i.v. injections of the drug (5 versus $90 \mathrm{~s}$ ) show greater desensitization of nicotine-evoked c-fos and arc mRNA expression in the nucleus accumbens shell and caudateputamen (Samaha et al., 2005). The functional significance of these changes is unknown. However, an interesting hypothesis is that the time-course of drug-induced plasticity in gene regulation might vary as a function of the speed of drug onset (Samaha et al., 2005). Variation in the speed of i.v. cocaine delivery also alters the brain expression of the neurotrophin, brain-derived neurotrophic factor (BDNF) and of its receptor, tropomyosin receptor kinase B (TrkB) (Bouayad-Gervais et al., 2014). Chronic exposure to cocaine and other psychostimulant drugs regulates brain BDNF mRNA and protein levels (Asan, 1997, Fumagalli et al., 2007, Grimm et al., 2003 and Im et al., 2010), and BDNF-mediated signalling specifically in midbrain and corticostriatal regions mediates drug-seeking and drugtaking behaviours (Graham et al., 2007, Graham et al., 2009, Im et al., 2010 and Unterwald et al., 2001). In rats given LgA session, only those taking rapid cocaine injections (5 versus $90 \mathrm{~s})$ show altered BDNF and TrkB mRNA levels in corticostriatal structures (caudate-putamen, orbitofrontal, frontal and parietal cortices, but not the nucleus accumbens or medial prefrontal cortex) (Bouayad-Gervais et al., 2014). At present, it remains unknown how the mRNA changes might translate to protein changes and whether increased regulation of BDNF and TrkB in corticostriatal nuclei plays a causal role in the behavioural effects of rapid cocaine delivery. Dopamine D2 receptor changes have also been reported in rats with a history of self-administering rapid versus more sustained cocaine injections during LgA sessions. Following 2 weeks of withdrawal from cocaine, rats with a history of taking slow 
cocaine injections have decreased D2 receptor levels in the caudate-putamen, and D2 receptors with greater agonist affinity (Minogianis et al., 2013). As with the BDNF-TrkB mRNA findings, additional work is needed to determine how the observed D2 receptor changes might contribute to the behavioural effects of the speed of cocaine delivery. Future studies can determine whether the D2-receptor related changes modify striatal signalling in ways that protect from excessive motivation to take cocaine (Minogianis et al., 2013).

How often drug levels rise and fall within a bout of drug selfadministration is also a prime determinant of drug effects on the brain. The intake of cocaine at short $(2 \mathrm{~min})$ rather than longer (6 min) intervals within each self-administration session preferentially increases c-Fos protein levels in the prelimbic and infralimbic cortices, the nucleus accumbens shell and core and the basolateral nucleus of the amygdala (Martin-Garcia et al., 2014). Optogenetic manipulations also show that neuronal activity within the prelimbic cortex regulates cocaine-seeking and -taking behaviours only in animals allowed to selfadminister cocaine at short inter-infusion intervals (MartinGarcia et al., 2014). This suggests that cocaine intake at short inter-infusion intervals promotes the ability of the prelimbic cortex to control drug use. Finally, Calipari et al., 2013 and Calipari et al., 2014 have assessed the influence of intermittent spikes in brain cocaine levels on the dopamine transporter (DAT). They compared LgA rats to IntA rats. IntA rats developed sensitization to the ability of cocaine, methylphenidate and methamphetamine to inhibit the DAT within the nucleus accumbens, while $\operatorname{LgA}$ rats developed tolerance to cocaine's effects at the transporter (Calipari et al., 2013 and Calipari et al., 2014). This is in agreement with studies using experimenter-administered drug and showing that intermittent access promotes sensitization of cocaine's effects on dopamine reuptake, while continuous access promotes tolerance (Izenwasser and Cox, 1990 and Izenwasser and Cox, 1992). The findings of Calipari et al., 2013 and Calipari et al., 2014 also concord with recent work showing that $\operatorname{LgA}$ rats show decreased phasic dopamine levels in the nucleus accumbens core (Willuhn et al., 2014).

\section{Why is it useful to study the temporal dynamics of drug delivery as an active principle in addiction?}

In attempting to reduce the enormous impact of drug addiction on health and society, the first step is to understand the factors that can modulate the development of the disorder. As the literature reviewed above demonstrates, in determining the effects of drugs on brain and behaviour, the dynamics of drug delivery are not just secondary to achieved dose or to the crossing of certain threshold levels of drug exposure. Instead, they determine brain and behaviour changes that are relevant to the addiction process. A growing literature suggests that, in keeping with clinical observations, animals that take drugs like cocaine in a pattern that produces rapidly rising and intermittent 'spikes' in brain levels of drug more readily develop an addiction phenotype. Thus, evidence is emerging to help us better understand what routes and patterns of drug administration are the most addictive. This information has tremendous implications. First, it can be used to identify vulnerable drug users most susceptible to progress towards addiction, allowing early intervention strategies to be implemented. Second, this work has implications for new treatment avenues. Pharmacokinetic principles are already exploited to treat addiction to some drugs (nicotine patch/gum versus smoking a cigarette; methadone versus heroin). Pharmacokinetic principles might also be used in the development of agents to treat addiction to drugs like cocaine. If spiking brain levels of drug do indeed contribute to addiction, pharmacological ways of flattening these spikes can be envisioned. Finally, upstream of this, data from the basic science literature can be used to educate the public and influence choices not only about whether to take drugs, but how. Scientists have long known that pharmacokinetics matter, the layperson might not. The public would benefit from education about the consequences of using certain routes, patterns of drug use and drug formulations.

\section{Where do we go from here?}

Great strides have been made in understanding the importance of pharmacokinetic factors in drug addiction, but important data are still missing. It is known that pharmacokinetics influence the behavioural response to drugs and some neurobiological correlates have been reported. However, the neurobiological findings remain largely correlational. There is little evidence on how specific brain changes might play a causal role in the ability of the speed of drug onset or the intermittency of drug use to influence behaviour. In parallel, we know little about what brain levels of drug look like when experienced drug users are given control over drug pharmacokinetics (e.g., dose, intermittency of dosing, speed of drug onset). Such information would be critical for the design of both representative brain imaging studies in humans and drug self-administration experiments in laboratory animals.

\section{Concluding remarks}

If we as drug addiction researchers ignore pharmacokinetics, we do so at our peril. There is strong evidence that chronic exposure to intermittent and rapidly rising brain levels of drug (cocaine in particular) promote an escalation in consummatory and appetitive responding for drug. This has notable parallels with the extensive literature on psychomotor sensitization, where there is agreement that intermittency of drug exposure and abstinence periods are key (Post, 1980 and Robinson and Becker, 1986). The ability of rapidly rising brain levels of drug to facilitate excessive patterns of drug use is associated with changes in gene regulation, dopamine neurochemistry and cell function that are thought to be important in the addiction process. In several instances, such rapidly spiking brain levels of drug were directly compared with high and sustained brain levels (e.g., IntA versus LgA). This work reveals that the two pharmacokinetic profiles produce different outcomes and that out of the two, drug 'spikes' appears to push the addiction process forward more effectively. This has profound implications for better understanding the neuroadaptations that 
are critical for addiction. There is a great amount of data on the ability of $\operatorname{LgA}$ procedures to promote changes in brain and behaviour. This model is currently dominating the literature on drug self-administration in animals (even in our own past work Bouayad-Gervais et al., 2014 and Minogianis et al., 2013), and it has shed important new light on how extensive exposure to sustained and high levels of drug change brain and behaviour. LgA is widely used because many would say that it has face validity since it produces escalation from more modest drug intake to binge use. However, as argued above, it is unlikely that human cocaine addicts have relatively free access to cocaine several hours a day, for days on end, enabling them to maintain high and sustained brain levels of drug. Rather, they might voluntarily achieve intermittently rising brain levels of drug during a bout of intoxication (Beveridge et al., 2012), and also use intermittently over time (Cohen and Sas, 1994 and O'Brien, 2001). Moreover, work in animals shows that continuously high versus intermittently high brain levels of cocaine can produce opposite effects on DA system function for example (Calipari et al., 2013 and Calipari et al., 2014). This deserves research attention, as we want to be sure which model more closely captures the way humans take drugs. The temporal pattern of drug use is of tremendous importance in addiction, particularly cocaine addiction, and this should be reflected in the animal models we use to study addiction in the laboratory.

\section{Conflict of interest statement}

The authors have no biomedical financial interests or conflicts of interest to declare.

\section{Acknowledgements}

ANS holds a salary award from the Fonds de la Recherche en Santé du Québec (Grant No. 28988). EAM holds a graduate fellowship from the Fonds de la Recherche en Santé du Québec (Grant No. 29651). ANS wishes to warmly thank Dr. Terry E. Robinson for inspiring her to investigate the role of kinetic factors in drug addiction.

\section{References}

Ahmed, S.H., 2012. The science of making drug-addicted animals. Neuroscience 211, 107-125.

Ahmed, S.H., Cador, M., 2006. Dissociation of psychomotor sensitization from compulsive cocaine consumption. Neuropsychopharmacology 31, 563-571.

Ahmed, S.H., Kenny, P.J., Koob, G.F., Markou, A., 2002. Neurobiological evidence for hedonic allostasis associated with escalating cocaine use. Nat. Neurosci. 5, 625-626.

Ahmed, S.H., Koob, G.F., 1998. Transition from moderate to excessive drug intake: change in hedonic set point. Science 282, 298-300.
Ahmed, S.H., Koob, G.F., 1999. Long-lasting increase in the set point for cocaine self-administration after escalation in rats. Psychopharmacology (Berl) 146, 303-312.

Ahmed, S.H., Koob, G.F., 2005. Transition to drug addiction: a negative reinforcement model based on an allostatic decrease in reward function. Psychopharmacology (Berl) 180, 473-490.

Asan, E., 1997. Ultrastructural features of tyrosinehydroxylase-immunoreactive afferents and their targets in the rat amygdala. Cell Tissue Res. 288, 449-469.

Baker, L.K., Mao, D., Chi, H., Govind, A.P., Vallejo, Y.F., Iacoviello, M., Herrera, S., Cortright, J.J., Green, W.N., McGehee, D.S., Vezina, P., 2013. Intermittent nicotine exposure upregulates nAChRs in VTA dopamine neurons and sensitises locomotor responding to the drug. Eur. J. Neurosci. 37, 1004-1011.

Barrio, G., De La Fuente, L., Lew, C., Royuela, L., Bravo, M.J., Torrens, M., 2001. Differences in severity of heroin dependence by route of administration: the importance of length of heroin use. Drug Alcohol Depend. 63, 169-177.

Bass, C.E., Jansen, H.T., Roberts, D.C., 2010. Free-running rhythms of cocaine self-administration in rats held under constant lighting conditions. Chronobiol. Int. 27, 535548.

Belin, D., Balado, E., Piazza, P.V., Deroche-Gamonet, V., 2009. Pattern of intake and drug craving predict the development of cocaine addiction-like behavior in rats. Biol. Psychiatry 65, 863-868.

Ben-Shahar, O., Ahmed, S.H., Koob, G.F., Ettenberg, A., 2004. The transition from controlled to compulsive drug use is associated with a loss of sensitization. Brain Res. 995, 4654.

Benowitz, N.L., Henningfield, J.E., 1994. Establishing a nicotine threshold for addiction. The implications for tobacco regulation. N. Engl. J. Med. 331, 123-125.

Berlin, I., Anthenelli, R.M., 2001. Monoamine oxidases and tobacco smoking. Int. J. Neuropsychopharmacol. 4, 3342.

Beveridge, T.J.R., Wray, P., Brewer, A., Shapiro, B., Mahoney, J.J., Newton, T.F., Haile, C.N., De La Garza II, R., 2012. Analyzing Human Cocaine Use Patterns to Inform Animal Addiction Model Development. College on Problems of Drug Dependence, Palm Springs, CA.

Bouayad-Gervais, K., Minogianis, E.A., Levesque, D., Samaha, A.N., 2014. The self-administration of rapidly delivered cocaine promotes increased motivation to take the drug: contributions of prior levels of operant responding and cocaine intake. Psychopharmacology (Berl) 231, 42414252. 
Brady, K.T., Lydiard, R.B., Malcolm, R., Ballenger, J.C., 1991. Cocaine-induced psychosis. J. Clin. Psychiatry 52, 509512.

Brebner, K., Phelan, R., Roberts, D.C., 2000. Effect of baclofen on cocaine self-administration in rats reinforced under fixed-ratio 1 and progressive-ratio schedules. Psychopharmacology (Berl) 148, 314-321.

Brown, P.L., Kiyatkin, E.A., 2005. Brain temperature change and movement activation induced by intravenous cocaine delivered at various injection speeds in rats. Psychopharmacology (Berl) 181, 299-308.

Budney, A.J., Higgins, S.T., Bickel, W., Kent, L., 1993. Relationship between intravenous use and achieving initial cocaine abstinence. Drug Alcohol Depend. 32, $133-142$.

Calipari, E.S., Ferris, M.J., Siciliano, C.A., Zimmer, B.A., Jones, S.R., 2014. Intermittent cocaine self-administration produces sensitization of stimulant effects at the dopamine transporter. J. Pharmacol. Exp. Ther. 349, 192198.

Calipari, E.S., Ferris, M.J., Zimmer, B.A., Roberts, D.C., Jones, S.R., 2013. Temporal pattern of cocaine intake determines tolerance vs sensitization of cocaine effects at the dopamine transporter. Neuropsychopharmacology 38, 2385-2392.

Carey, R., Gui, J., 1998. Cocaine sensitization can accelerate the onset of peak cocaine behavioral effects. Pharmacol. Biochem. Behav. 60, 395-405.

Carpenter, M.J., Chutuape, M.A., Stitzer, M.L., 1998. Heroin snorters versus injectors: comparison on drug use and treatment outcome in age-matched samples. Drug Alcohol Depend. 53, 11-15.

Cohen, A., Koob, G.F., George, O., 2012. Robust escalation of nicotine intake with extended access to nicotine selfadministration and intermittent periods of abstinence. Neuropsychopharmacology 37, 2153-2160.

Cohen, P., Sas, A., 1994. Cocaine use in Amsterdam in non deviant subcultures. Addict. Res. 2, 71-94.

Cone, E.J., 1995. Pharmacokinetics and pharmacodynamics of cocaine. J. Anal. Toxicol. 19, 459-478.

Cone, E.J., 1998. Recent discoveries in pharmacokinetics of drugs of abuse. Toxicol. Lett. 102-103, 97-101.

Connor, D.F., Steingard, R.J., 2004. New formulations of stimulants for attention-deficit hyperactivity disorder: therapeutic potential. CNS Drugs 18, 1011-1030.

Crombag, H.S., Ferrario, C.R., Robinson, T.E., 2008. The rate of intravenous cocaine or amphetamine delivery does not influence drug-taking and drug-seeking behavior in rats. Pharmacol. Biochem. Behav. 90, 797-804.

Deroche-Gamonet, V., Belin, D., Piazza, P.V., 2004. Evidence for addiction-like behavior in the rat. Science 305, 10141017.

Di Chiara, G., 2000. Behavioural pharmacology and neurobiology of nicotine reward and dependence. In: Clementi, F., Fornasari, D., Gotti, C. (Eds.), Handbook of Experimental Pharmacology. Springer, Heidelberg.

Downs, A.W., Eddy, N.B., 1932. The effect of repeated doses of cocaine on the rat. J. Pharmacol. Exp. Ther. 46, 199200 .

Eikelboom, R., Stewart, J., 1982. Conditioning of drug-induced physiological responses. Psychol. Rev. 89, 507-528.

Espana, R.A., Oleson, E.B., Locke, J.L., Brookshire, B.R., Roberts, D.C., Jones, S.R., 2010. The hypocretin-orexin system regulates cocaine self-administration via actions on the mesolimbic dopamine system. Eur. J. Neurosci. 31, 336-348.

Evans, S.M., Cone, E.J., Henningfield, J.E., 1996. Arterial and venous cocaine plasma concentrations in humans: relationship to route of administration, cardiovascular effects and subjective effects. J. Pharmacol. Exp. Ther. 279, 1345-1356.

Ferrario, C.R., Gorny, G., Crombag, H.S., Li, Y., Kolb, B., Robinson, T.E., 2005. Neural and behavioral plasticity associated with the transition from controlled to escalated cocaine use. Biol. Psychiatry 58, 751-759.

Ferrario, C.R., Robinson, T.E., 2007. Amphetamine pretreatment accelerates the subsequent escalation of cocaine self-administration behavior. Eur. Neuropsychopharmacol. 17, 352-357.

Ferrario, C.R., Shou, M., Samaha, A.N., Watson, C.J., Kennedy, R.T., Robinson, T.E., 2008. The rate of intravenous cocaine administration alters c-fos mRNA expression and the temporal dynamics of dopamine, but not glutamate, overflow in the striatum. Brain Res. 1209, $151-156$.

Ferri, C.P., Gossop, M., 1999. Route of cocaine administration: patterns of use and problems among a Brazilian sample. Addict. Behav. 24, 815-821.

Fitch, T.E., Roberts, D.C., 1993. The effects of dose and access restrictions on the periodicity of cocaine selfadministration in the rat. Drug Alcohol Depend. 33, 119128.

Fumagalli, F., Di Pasquale, L., Caffino, L., Racagni, G., Riva, M.A., 2007. Repeated exposure to cocaine differently modulates BDNF $\mathrm{mRNA}$ and protein levels in rat striatum and prefrontal cortex. Eur. J. Neurosci. 26, 2756-2763. 
Gawin, F.H., 1991. Cocaine addiction: psychology and neurophysiology. Science 251, 1580-1586.

Gawin, F.H., Kleber, H.D., 1986. Abstinence symptomatology and psychiatric diagnosis in cocaine abusers. Clinical observations. Arch. Gen. Psychiatry 43, 107-113.

Gossop, M., Griffiths, P., Powis, B., Strang, J., 1992. Severity of dependence and route of administration of heroin, cocaine and amphetamines. Br. J. Addict. 87, 1527-1536.

Gossop, M., Griffiths, P., Powis, B., Strang, J., 1994. Cocaine: patterns of use, route of administration, and severity of dependence. Br. J. Psychiatry 164, 660-664.

Graham, D.L., Edwards, S., Bachtell, R.K., Dileone, R.J., Rios, M., Self, D.W., 2007. Dynamic BDNF activity in nucleus accumbens with cocaine use increases self-administration and relapse. Nat. Neurosci. 10, 1029-1037.

Graham, D.L., Krishnan, V., Larson, E.B., Graham, A., Edwards, S., Bachtell, R.K.,Simmons, D., Gent, L.M., Berton, O., Bolanos, C.A., DiLeone, R.J., Parada, L.F.,Nestler, E.J., Self, D.W., 2009. Tropomyosin-related kinase $\mathrm{B}$ in the mesolimbic dopamine system: regionspecific effects on cocaine reward. Biol. Psychiatry65, 696-701.

Grimm, J.W., Lu, L., Hayashi, T., Hope, B.T., Su, T.P., Shaham, Y., 2003. Time-dependent increases in brainderived neurotrophic factor protein levels within the mesolimbic dopamine system after withdrawal from cocaine: implications for incubation of cocaine craving. J. Neurosci. 23, 742-747.

Hao, Y., Martin-Fardon, R., Weiss, F., 2010. Behavioral and functional evidence of metabotropic glutamate receptor $2 / 3$ and metabotropic glutamate receptor 5 dysregulation in cocaine-escalated rats: factor in the transition to dependence. Biol. Psychiatry 68, 240-248.

Hatsukami, D.K., Fischman, M.W., 1996. Crack cocaine and cocaine hydrochloride. Are the differences myth or reality? JAMA 276, 1580-1588.

Hodos, W., 1961. Progressive ratio as a measure of reward strength. Science 134,943-944.

Hollander, J.A., Carelli, R.M., 2005. Abstinence from cocaine self-administration heightens neural encoding of goaldirected behaviors in the accumbens. Neuropsychopharmacology 30, 1464-1474.

Hooks, M.S., Duffy, P., Striplin, C., Kalivas, P.W., 1994. Behavioral and neurochemical sensitization following cocaine self-administration. Psychopharmacology (Berl) $115,265-272$.

Horger, B.A., Shelton, K., Schenk, S., 1990. Preexposure sensitizes rats to the rewarding effects of cocaine. Pharm. Biochem. Behav. 37, 707-711.
Hughes, J.R., 1989. Dependence potential and abuse liability of nicotine replacement therapies. Biomed. Pharmacother. 43, 11-17.

Im, H.I., Hollander, J.A., Bali, P., Kenny, P.J., 2010. MeCP2 controls BDNF expression and cocaine intake through homeostatic interactions with microRNA-212. Nat. Neurosci. 13, 1120-1127.

Izenwasser, S., Cox, B.M., 1990. Daily cocaine treatment produces a persistent reduction of $[3 \mathrm{H}]$ dopamine uptake in vitro in rat nucleus accumbens but not in striatum. Brain Res. 531, 338-341.

Izenwasser, S., Cox, B.M., 1992. Inhibition of dopamine uptake by cocaine and nicotine: tolerance to chronic treatments. Brain Res. 573, 119-125.

Jaffe, J.H., Cascella, N.G., Kumor, K.M., Sherer, M.A., 1989. Cocaine-induced cocaine craving. Psychopharmacology (Berl) 97, 59-64.

Javaid, J.I., Fischman, M.W., Schuster, C.R., Dekirmenjian, H., Davis, J.M., 1978. Cocaine plasma concentration: relation to physiological and subjective effects in humans. Science 202, 227-228.

Javaid, J.I., Musa, M.N., Fischman, M., Schuster, C.R., Davis, J.M., 1983. Kinetics of cocaine in humans after intravenous and intranasal administration. Biopharm. Drug Dispos. 4, 9-18.

Jeffcoat, A.R., Perez-Reyes, M., Hill, J.M., Sadler, B.M., Cook, C.E., 1989. Cocaine disposition in humans after intravenous injection, nasal insufflation (snorting), or smoking. Drug Metab. Dispos. 17, 153-159.

Jones, R.T., 1990. The pharmacology of cocaine smoking in humans. NIDA Res.Monogr. 99, 30-41, Source: National Institute on Drug Abuse; National Institutes of Health; U.S. Department of Health and Human Services.

Jones, S.R., Lee, T.H., Wightman, R.M., Ellinwood, E.H., 1996. Effects of intermittent and continuous cocaine administration on dopamine release and uptake regulation in the striatum: in vitro voltammetric assessment. Psychopharmacology (Berl) 126, 331-338.

Jonkman, S., Pelloux, Y., Everitt, B.J., 2012. Drug intake is sufficient, but conditioning is not necessary for the emergence of compulsive cocaine seeking after extended self-administration. Neuropsychopharmacology 37, 16121619 .

Kato, S., Wakasa, Y., Yanagita, T., 1987. Relationship between minimum reinforcing doses and injection speed in cocaine and pentobarbital self-administration in crab-eating monkeys. Pharmacol. Biochem. Behav. 28, 407-410.

Kippin, T.E., Fuchs, R.A., See, R.E., 2006. Contributions of prolonged contingent and non contingent cocaine 
exposure to enhanced reinstatement of cocaine seeking in rats. Psychopharmacology (Berl) 187, 60-67.

Knackstedt, L.A., Kalivas, P.W., 2007. Extended access to cocaine self-administration enhances drug-primed reinstatement but not behavioral sensitization. J. Pharmacol. Exp. Ther. 322 (3), 1103-1109.

Kuczenski, R., Segal, D.S., 1988. Psychomotor stimulantinduced sensitization: behavioral and neurochemical correlates. In: Kalivas, P.W., Barnes, C.D. (Eds.), Sensitization in the Nervous System. Telford Press, Caldwell, NJ, pp.175-205.

Lett, B.T., 1989. Repeated exposures intensify rather than diminish the rewarding effects of amphetamine, morphine, and cocaine. Psychopharmacology (Berlin) 98, $357-362$.

Liu, Y., Roberts, D.C., Morgan, D., 2005a. Effects of extendedaccess self-administration and deprivation on breakpoints maintained by cocaine in rats. Psychopharmacology (Berl) 179, 644-651.

Liu, Y., Roberts, D.C., Morgan, D., 2005b. Sensitization of the reinforcing effects of self-administered cocaine in rats: effects of dose and intravenous injection speed. Eur. J. Neurosci. 22, 195-200.

Loh, E.A., Roberts, D.C., 1990. Break-points on a progressive ratio schedule reinforced by intravenous cocaine increase following depletion of forebrain serotonin. Psychopharmacology (Berl) 101, 262-266.

Lorrain, D.S., Arnold, G.M., Vezina, P., 2000. Previous exposure to amphetamine increases incentive to obtain the drug: long-lasting effects revealed by the progressive ratio schedule. Behav. Brain Res. 107, 9-19.

Mantsch, J.R., Yuferov, V., Mathieu-Kia, A.M., Ho, A., Kreek, M.J., 2004. Effects of extended access to high versus low cocaine doses on self-administration, cocaine-induced reinstatement and brain mRNA levels in rats. Psychopharmacology (Berl) 175, 26-36.

Martin-Garcia, E., Courtin, J., Renault, P., Fiancette, J.F., Wurtz, H., Simonnet, A.,Levet, F., Herry, C., DerocheGamonet, V., 2014. Frequency of cocaine selfadministration influences drug seeking in the rat: optogenetic evidence for a role of the prelimbic cortex. Neuropsychopharmacology 39 (10), 2317-2330.

Mendrek, A., Blaha, C.D., Phillips, A.G., 1998. Pre-exposure of rats to amphetamine sensitizes self-administration of this drug under a progressive ratio schedule. Psychopharmacology (Berl) 135, 416-422.

Minogianis, E.A., Levesque, D., Samaha, A.N., 2013. The speed of cocaine delivery determines the subsequent motivation to self-administer the drug. Neuropsychopharmacology 38 (13), 2644-2656.

Morgan, D., Brebner, K., Lynch, W.J., Roberts, D.C., 2002. Increases in the reinforcing efficacy of cocaine after particular histories of reinforcement. Behav. Pharmacol. 13, 389-396.

Morgan, D., Liu, Y., Roberts, D.C., 2006. Rapid and persistent sensitization to the reinforcing effects of cocaine. Neuropsychopharmacology 31, 121-128.

Morgan, D., Roberts, D.C., 2004. Sensitization to the reinforcing effects of cocaine following binge-abstinent self-administration. Neurosci. Biobehav. Rev. 27,803812 .

Morgan, D., Smith, M.A., Roberts, D.C., 2005. Binge selfadministration and deprivation produces sensitization to the reinforcing effects of cocaine in rats. Psychopharmacology (Berl) 178, 309-316.

Negus, S.S., Henningfield, J., 2015. Agonist medications for the treatment of cocaine use disorder. Neuropsychopharmacology (Epub).

Neugebauer, N.M., Cortright, J.J., Sampedro, G.R., Vezina, P., 2014. Exposure to nicotine enhances its subsequent selfadministration: contribution of nicotine-associated contextual stimuli. Behav. Brain Res. 260, 155-161.

Nicola, S.M., Deadwyler, S.A., 2000. Firing rate of nucleus accumbens neurons is dopamine-dependent and reflects the timing of cocaine-seeking behavior in rats on a progressive ratio schedule of reinforcement. J. Neurosci. 20, 5526-5537.

Nomikos, G.G., Spyraki, C., 1988. Cocaine-induced place conditioning: importance of route of administration and other procedural variables. Psychopharmacology (Berl) 94, 119-125.

O'Brien, C., 2001. Drug Addiction and Drug Dependence, Goodman and Gilman's: The Pharmacological Basis of Therapeutics, 10th ed. McGraw-Hill, New York, NY.

O’Brien, C.P., 2008. Review. Evidence-based treatments of addiction. Philos. Trans. R. Soc. London, Ser., B: Biol. Sci. 363, 3277-3286.

O’Brien, C.P., Childress, A.R., McLellan, A.T., Ehrman, R., 1992. Classical conditioning in drug-dependent humans. Ann. N.Y. Acad. Sci. 654, 400-415.

Oleson, E.B., Roberts, D.C., 2009. Behavioral economic assessment of price and cocaine consumption following self-administration histories that produce escalation of either final ratios or intake. Neuropsychopharmacology 34,796-804. 
Pan, H.T., Menacherry, S., Justice Jr., J.B., 1991. Differences in the pharmacokinetics of cocaine in naive and cocaineexperienced rats. J. Neurochem. 56, 1299-1306.

Paterson, N.E., Markou, A., 2003. Increased motivation for self-administered cocaine after escalated cocaine intake. NeuroReport 14, 2229-2232.

Phillips, A.G., Di Ciano, P., 1996. Behavioral sensitization is induced by intravenous self-administration of cocaine by rats. Psychopharmacology (Berl) 124,279-281.

Piazza, P.V., Deminière, J.M., Le Moal, M., Simon, H., 1990. Stress- and pharmacologically-induced behavioral sensitization increases vulnerability to acquisition of amphetamine self-administration. Brain Res. 514, 22-26.

Pickens, R., Thompson, T., 1968. Cocaine-reinforced behavior in rats: effects of reinforcement magnitude and fixed-ratio size. J. Pharmacol. Exp. Ther. 161,122-129.

Pierre, P.J., Vezina, P., 1997. Predisposition to self-administer amphetamine: the contribution of response to novelty and prior exposure to the drug. Psychopharmacology (Berl) $129,277-284$.

Pierre, P.J., Vezina, P., 1998. D1 dopamine receptor blockade prevents the facilitation of amphetamine selfadministration induced by prior exposure to the drug. Psychopharmacology (Berl) 138, 159-166.

Porrino, L.J., 1993. Functional consequences of acute cocaine treatment depend on route of administration. Psychopharmacology (Berl) 112, 343-351.

Post, R.M., 1980. Intermittent versus continuous stimulation: effect of time interval on the development of sensitization or tolerance. Life Sci. 26, 1275-1282.

Post, R.M., Rose, H., 1976. Increasing effects of repetitive cocaine administration in the rat. Nature 260, 731-732.

Rawson, R.A., Gonzales, R., Marinelli-Casey, P., Ang, A., 2007. Methamphetamine dependence: a closer look at treatment response and clinical characteristics associated with route of administration in outpatient treatment. Am. J. Addict.16, 291-299.

Reith, M.E., Benuck, M., Lajtha, A., 1987. Cocaine disposition in the brain after continuous or intermittent treatment and locomotor stimulation in mice. J. Pharmacol. Exp. Ther. 243, 281-287.

Richardson, N.R., Roberts, D.C., 1996. Progressive ratio schedules in drug self-administration studies in rats: a method to evaluate reinforcing efficacy. J. Neurosci. Methods 66, 1-11.

Roberts, D.C., 1989. Breaking points on a progressive ratio schedule reinforced by intravenous apomorphine increase daily following 6-hydroxydopaminelesions of the nucleus accumbens. Pharmacol. Biochem. Behav. 32, 43-47.

Roberts, D.C., Bennett, S.A., Vickers, G.J., 1989. The estrous cycle affects cocaine self-administration on a progressive ratio schedule in rats. Psychopharmacology (Berl) 98, 408-411.

Roberts, D.C., Brebner, K., Vincler, M., Lynch, W.J., 2002. Patterns of cocaine self-administration in rats produced by various access conditions under a discrete trials procedure. Drug Alcohol Depend. 67, 291-299.

Roberts, D.C., Gabriele, A., Zimmer, B.A., 2013. Conflation of cocaine seeking and cocaine taking responses in IV selfadministration experiments in rats: methodological and interpretational considerations. Neurosci. Biobehav. Rev.37, 2026-2036.

Roberts, D.C., Loh, E.A., Baker, G.B., Vickers, G., 1994. Lesions of central serotonin systems affect responding on a progressive ratio schedule reinforced either by intravenous cocaine or by food. Pharmacol. Biochem. Behav. 49, 177-182.

Robinson, T.E., Becker, J.B., 1986. Enduring changes in brain and behavior produced by chronic amphetamine administration: a review and evaluation of animal models of amphetamine psychosis. Brain Res. 396, 157-198.

Robinson, T.E., Berridge, K.C., 1993. The neural basis of drug craving: an incentive-sensitization theory of addiction. Brain Res. Brain Res. Rev. 18,247-291.

Robinson, T.E., Berridge, K.C., 2000. The psychology and neurobiology of addiction: an incentive-sensitization view. Addiction 95 (Suppl. 2), S91-S117.

Roncero, C., Ros-Cucurull, E., Daigre, C., Casas, M., 2012. Prevalence and risk factors of psychotic symptoms in cocaine-dependent patients. Actas Esp. Psiquiatr. 40,187197.

Russell, M.A., Feyerabend, C., 1978. Cigarette smoking: a dependence on high-nicotine boli. Drug Metab. Rev. 8, $29-57$.

Samaha, A.N., Li, Y., Robinson, T.E., 2002. The rate of intravenous cocaine administration determines susceptibility to sensitization. J. Neurosci. 22, 3244-3250.

Samaha, A.N., Mallet, N., Ferguson, S.M., Gonon, F., Robinson, T.E., 2004. The rate of cocaine administration alters gene regulation and behavioral plasticity: implications for addiction. J. Neurosci. 24, 6362-6370.

Samaha, A.N., Yau, W.Y., Yang, P., Robinson, T.E., 2005. Rapid delivery of nicotine promotes behavioral sensitization and alters its neurobiological impact. Biol. Psychiatry 57, 351-360. 
Schindler, C.W., Cogan, E.S., Thorndike, E.B., Panlilio, L.V., 2011. Rapid delivery of cocaine facilitates acquisition of self-administration in rats: an effect masked by paired stimuli. Pharmacol. Biochem. Behav. 99, 301-306.

Schindler, C.W., Panlilio, L.V., Thorndike, E.B., 2009. Effect of rate of delivery of intravenous cocaine on selfadministration in rats. Pharmacol. Biochem. Behav. 93, $375-381$.

Segal, D.S., Geyer, M.A., Schuckit, M.A., 1981. Stimulantinduced psychosis: an evaluation of animal models. Essays Neurochem. Neuropharmacol. 5, 95-129.

Siegel, S., 1977. Learning and psychopharmacology. In: Jarvik, M.E. (Ed.), Psychopharmacology in the Practice of Medicine. Appleton-Century-Crofts, New York, NY.

Sorge, R.E., Clarke, P.B., 2009. Rats self-administer intravenous nicotine delivered in a novel smokingrelevant procedure: effects of dopamine antagonists. J. Pharmacol. Exp. Ther. 330, 633-640.

Spencer, T.J., Biederman, J., Ciccone, P.E., Madras, B.K., Dougherty, D.D., Bonab, A.A., Livni, E., Parasrampuria, D.A., Fischman, A.J., 2006. PET study examining pharmacokinetics, detection and likeability, and dopamine transporter receptor occupancy of short- and long-acting oral methylphenidate. Am. J. Psychiatry 163, 387-395.

Spyraki, C., Fibiger, H.C., Phillips, A.G., 1982. Cocaineinduced place preference conditioning: lack of effects of neuroleptics and 6-hydroxydopamine lesions. Brain Res. 253, 195-203.

Spyraki, C., Nomikos, G.G., Varonos, D.D., 1987. Intravenous cocaine-induced place preference: attenuation by haloperidol. Behav. Brain Res. 26, 57-62.

Stewart, J., Badiani, A., 1993. Tolerance and sensitization to the behavioral effects of drugs. Behav. Pharmacol. 4, 289-312.

Unterwald, E.M., Kreek, M.J., Cuntapay, M., 2001. The frequency of cocaine administration impacts cocaineinduced receptor alterations. Brain Res. 900, 103-109.

Van Dyke, C., Barash, P.G., Jatlow, P., Byck, R., 1976. Cocaine: plasma concentrations after intranasal application in man. Science 191, 859-861.

Van Dyke, C., Byck, R., 1982. Cocaine. Sci. Am. 246, 128 141.

Vanderschuren, L.J., Everitt, B.J., 2004. Drug seeking becomes compulsive after prolonged cocaine self-administration. Science 305, 1017-1019.

Vezina, P., 2004. Sensitization of midbrain dopamine neuron reactivity and the self-administration of psychomotor stimulant drugs. Neurosci. Biobehav. Rev.27, 827-839.
Vezina, P., Lorrain, D.S., Arnold, G.M., Austin, J.D., Suto, N., 2002. Sensitization of midbrain dopamine neuron reactivity promotes the pursuit of amphetamine. J. Neurosci. 22, 4654-4662.

Vezina, P., McGehee, D.S., Green, W.N., 2007. Exposure to nicotine and sensitization of nicotine-induced behaviors. Prog. Neuropsychopharmacol. Biol. Psychiatry 31, 16251638.

Volkow, N.D., Swanson, J.M., 2003. Variables that affect the clinical use and abuse of methylphenidate in the treatment of ADHD. Am. J. Psychiatry 160, 1909-1918.

Volkow, N.D., Wang, G.J., Fischman, M.W., Foltin, R., Fowler, J.S., Franceschi, D.,Franceschi, M., Logan, J., Gatley, S.J., Wong, C., Ding, Y.S., Hitzemann, R.,Pappas, N., 2000. Effects of route of administration on cocaine induced dopamine transporter blockade in the human brain. Life Sci. 67, 1507-1515.

Wakabayashi, K.T., Weiss, M.J., Pickup, K.N., Robinson, T.E., 2010. Rats markedly escalate their intake and show a persistent susceptibility to reinstatement only when cocaine is injected rapidly. J. Neurosci. 30, 11346-11355.

Ward, A.S., Haney, M., Fischman, M.W., Foltin, R.W., 1997. Binge cocaine self-administration in humans: intravenous cocaine. Psychopharmacology (Berl) 132, 375-381.

Wee, S., Mandyam, C.D., Lekic, D.M., Koob, G.F., 2008. Alpha 1-noradrenergicsystem role in increased motivation for cocaine intake in rats with prolonged access. Eur. Neuropsychopharmacol. 18, 303-311.

Willuhn, I., Burgeno, L.M., Groblewski, P.A., Phillips, P.E., 2014. Excessive cocaine use results from decreased phasic dopamine signaling in the striatum. Nat. Neurosci. 17, 704-709.

Wilson, M.C., Hitomi, M., Schuster, C.R., 1971. Psychomotor stimulant self-administration as a function of dosage per injection in the rhesus monkey. Psychopharmacologia 22, 271-281.

Winger, G., Hofmann, G.G., Woods, J.H., 1992. A Handbook on Drug and Alcohol Abuse: The Biomedical Aspects. Oxford UP, New York, PL.

Wise, R.A., Newton, P., Leeb, K., Burnette, B., Pocock, D., Justice Jr., J.B., 1995. Fluctuations in nucleus accumbens dopamine concentration during intravenous cocaine selfadministration in rats. Psychopharmacology (Berl) 120, $10-20$.

Woolverton, W.L., Wang, Z., 2004. Relationship between injection duration, transporter occupancy and reinforcing strength of cocaine. Eur. J. Pharmacol.486, 251-257. 
Zernig, G., 1997. Rate of rise in brain concentration determines reinforcing strength of cocaine in only $63 \%$ of tested rats. NIDA Res. Monogr. 178,218.

Zimmer, B.A., Oleson, E.B., Roberts, D.C., 2012. The motivation to self-administer is increased after a history of spiking brain levels of cocaine.

Neuropsychopharmacology 37, 1901-1910. 